\title{
LETTERS
}

\section{Emotion processing in the minimally conscious state}

As a newly described condition distinct from coma or the vegetative state, minimally conscious state (MCS) is characterised by a threshold level of consciousness, and diagnostic criteria have recently been proposed.' In MCS, cognitively mediated behaviour occurs inconsistently, but is reproducible or sustained enough to be differentiated from reflexive behaviour. It is clinically essential to distinguish this condition from persistent vegetative state (PVS), due to a potentially more favourable outcome. ${ }^{1}$ So far, whether patients in MCS can process emotion is unknown.

Cortical processing has been described in PVS using auditory and visual functional paradigms with positron emission tomography. ${ }^{23}$ However, to date hardly any functional imaging studies are available in patients in MCS. $^{4}$ We used fMRI to assess brain activity induced by an emotional stimulus in a patient in MCS.

A 17 year old man was riding his bicycle when he was hit by a train. The accident resulted in head trauma and immediate coma, progressing to MCS over the course of 4 months, when he was admitted to our institution. This research protocol was approved by the Institutional Ethics Committee. At the time of the fMRI study, 5 months after the accident, the patient localised noxious stimuli, had spontaneous eye opening, detectable sleep/wake cycles, sustained visual fixation, and contingent smiling, thus meeting criteria for MCS. A structural MRI study showed mild cortical atrophy and dilated ventricles. Auditory evoked potentials showed decreased conduction velocities at brainstem level. The patient increased his level of awareness 2.5 months after the functional study was conducted. Auditory evoked potentials after recovery were within normal range, while MRI showed much less ventricle dilatation. Six months after recovering full consciousness, he was able to chat normally and feed himself. Currently we are retesting the patient with the same paradigm.

Non-familiar voice $v$ silence and mother's voice $v$ non-familiar voice recognition were tested in an fMRI block design with 30 seconds per epoch. The patient listened to his

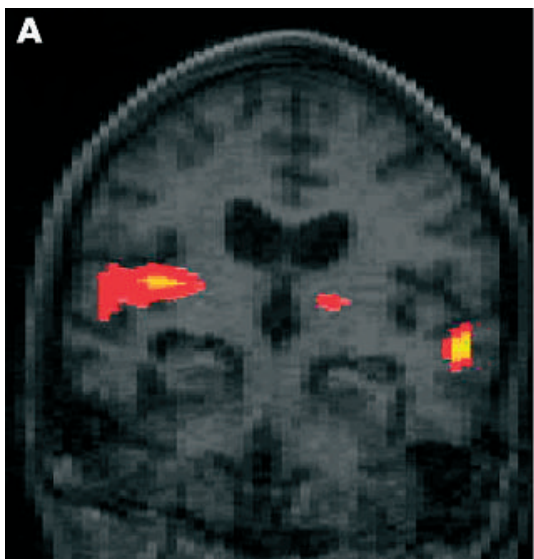

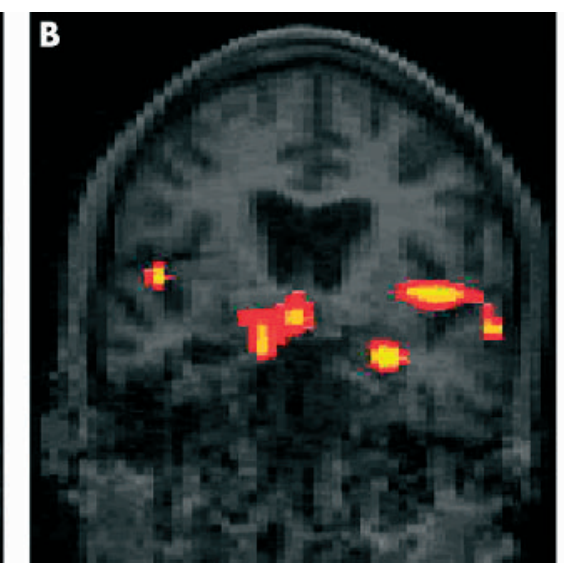

mother reading a story, followed 30 seconds later by an age matched voice reading the same story, for 30 seconds with silence epochs in between. Blood oxygen level dependent images were acquired using a $\mathrm{T}_{2}$ weighted gradient echo planar sequence on a General Electric Signa CVI, 1.5 T system with real time image processing of multislice and multiphase images during patient stimulation and rest periods. The Medx 3.4 Sensor System was used to carry out fMRI post-processing, including motion correction and Gaussian smoothing. An uncorrected significance threshold of $\mathrm{P}<0.001$ was used because amygdala and insula activation was expected, owing to emotional voice processing. Activated clusters were localised following co-registration with an anatomical $\mathrm{T}_{1}$-IR volume.

Subtraction of the phrases read by the age matched voice from silence was the control experiment, showing a significant focus of activation in the transverse and superior temporal gyri, which spread to the planum temporale; more anterior activation was found in the superior (right) and inferior (left) insula (fig 1A). The subtraction of the mother's phrases from the age matched voice disclosed a strong activation of the amygdala and insula spreading to the inferior frontal gyrus; there was also weaker activation of the transverse temporal gyrus, temporal operculum, and planum temporale (fig $1 \mathrm{~B}, \mathrm{C}$ ). Activation was lower on the right hemisphere in both comparisons, non-familiar voice $v$ silence and familiar voice $v$ non-familiar.

To the best of our knowledge, our results provide for the first time anatomical evidence for the response of an MCS patient to a familiar voice, in which both amygdala and insula appear to play a major role.

The activation pattern of the control experiment agrees with previous studies. Our results showed that the mother's voice activates the extended amygdala, an emotionally related structure, and a directly connected area such as the insula, perhaps acting jointly as limbic integration cortex. Although residual cerebral activity was unequivocal in our case, representing fragmentary cognitive processing, it should not be assumed that it depicts a fully integrated system required for normal levels of awareness; however, our findings highlight the legal and ethical implications of careless bedside chatter. Whether functional imaging represents a reliable method to evaluate neural processing in MCS patients, in whom cognitive output is extremely difficult to assess, remains to be seen.

T Bekinschtein, J Niklison, L Sigman, F Manes Cognitive Neurology Section, Institute for Neurological Research (FLENI), Buenos Aires, Argentina

R Leiguarda, F Manes

Department of Neurology, Institute for Neurological Research (FLENI), Buenos Aires, Argentina

J Armony

Department of Experimental Psychology, McGill University, Montreal, Canada

A Owen

MRC-CBU, Cambridge, UK

S Carpintiero

Functional Neuroimaging Laboratory, Institute for Neurological Research (FLENI), Buenos Aires, Argentina

L Olmos, F Manes

Rehabilitation Institute (FLENI), Buenos Aires, Argentina

Correspondence to: Dr F Manes, Cognitive Neurology Section, Institute for Neurological Research (FLENI), Montañeses 2325 (Cl428AQK). Buenos Aires,

Argentina; fmanes@fleni.org.ar

doi: 10.1136/jnnp.2003.034876

Received 22 December 2003 Revised 12 February 2004 Accepted 13 February 2004

This work was supported by the Institute for Neurological Research, FLENI.

Competing interests: none declared

\section{References}

1 Giacino JT, Ashwal S, Childs N, et al. The minimally conscious state: definition and diagnostic criteria. Neurology 2002;58:349-53.

2 de Jong BM, Willemsen AT, Paans AM. Regional cerebral blood flow changes related to affective speech presentation in persistent vegetative state. Clin Neurol Neurosurg 1997:99:213-16.

3 Menon DK, Owen AM, Williams EJ, et al. Cortical processing in persistent vegetative state. Wolfson Brain Imaging Centre Team. Lancet 1998;352:200.

4 Boly M, Faymonville ME, Peigneux $\mathrm{P}$, et al. Auditory processing in severely brain injured patients: differences between the minimally conscious state and the persistent vegetative state. Arch Neurol 2004:61:233-8.

5 Laureys S, Faymonville ME, Degueldre C, et al. Auditory processing in the vegetative state. Brain 2000;123:1589-601.

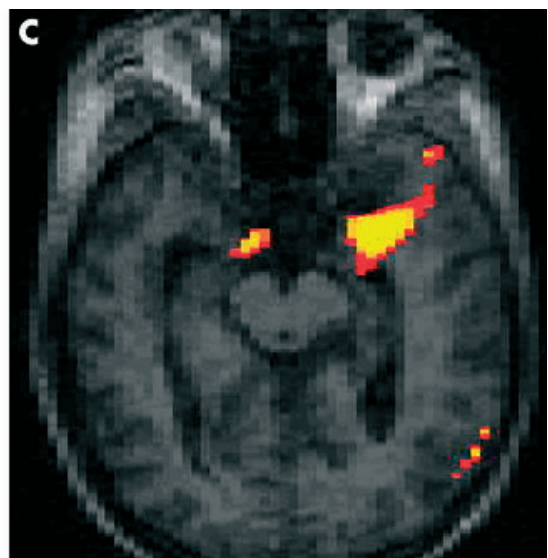

Figure 1 Brain areas of activation produced by non-familiar voice subtracted from silence in coronal view (control experiment, A). Brain areas of activation produced by mother's voice subtracted from non-familiar voice in coronal view (B), and in axial view (C) 


\section{Neurosyphilis presenting with gummatous oculomotor nerve palsy}

Although epidemiological studies suggest that the incidence of primary syphilis is rising, ${ }^{1}$ neurosyphilis remains an uncommon manifestation of Treponema pallidum infection. In addition, the MRI appearances of this treatable neurological condition are not well known. Many patients with neurosyphilis are asymptomatic, but manifestations include subacute basal meningitis, a meningovascular syndrome of small deep cerebral and cranial nerve infarctions, chronic gummatous inflammation with focal intracranial mass lesions, chronic comportmental dementia of general paresis, and chronic sensory-ataxic myelopathy of tabes dorsalis. We report a case in which a meningeal form of neurosyphilis presented with rapid evolution of a pupil-involving oculomotor nerve palsy to highlight the clinical, CSF, and MRI features and good response to treatment.

\section{Case report}

The patient was a 54 year old right handed homosexual man with a history of syphilis of unknown stage, treated with penicillin 25 years previously. He was well until 6 weeks prior to evaluation when he sustained minor head trauma in an automobile accident, followed by intermittent headaches, fatigue, photophobia, and anorexia. Four days before admission he developed worsening and persistent drooping of the right eyelid and double vision. On examination, his mental status was remarkable only for psychomotor slowing. The right pupil was round but enlarged at $6 \mathrm{~mm}$ and sluggishly constricted to $5 \mathrm{~mm}$ with direct and consensual light stimulation as well as near vision. The left pupil was round and $4 \mathrm{~mm}$ and constricted briskly to $2 \mathrm{~mm}$ to light. The right eye showed moderate ptosis of the upper lid, and the globe was deviated laterally in primary gaze with markedly impaired adduction and elevation. In the left eye, ptosis was absent and ocular motility was normal. Other cranial nerve, sensory, motor, and reflex functions and gait were normal with the exception of a slight decrease in vibration and position sense in the feet. There were no signs of meningeal irritation. Head computed tomography (CT) and CT angiography revealed neither blood in the subarachnoid space nor evidence of intracranial aneurysm. MRI of the head (fig 1) showed a spheroid contrastenhancing lesion at the root of the right oculomotor nerve, which extended towards the cavernous sinus. Incidentally noted were right cerebellar and right frontal developmental venous anomalies. CSF examination revealed normal opening pressure at lumbar puncture, 344 white blood cells (WBCs) (95\% lymphocytes), 14 red blood cells (RBCs), protein of $167 \mathrm{mg} \%$, and glucose of 39 mg\%. CSF Venereal Disease Research Laboratory test (VDRL) was positive at $1: 8$ whereas serum Rapid Plasma Reagin (RPR) was positive at 1:64. HIV testing was negative. Treatment with intravenous penicillin G (4 million Units every 6 hours) was administered for 2 weeks. By treatment day 4, the adduction and elevation of the right eye were improving. At 1 month follow up, mild fatigue persisted. There was trace right ptosis. Elevation and adduction of the right eye had improved to nearly normal, but the pupil remained $6 \mathrm{~mm}$ and sluggishly responsive to light. Repeat CSF examination showed seven
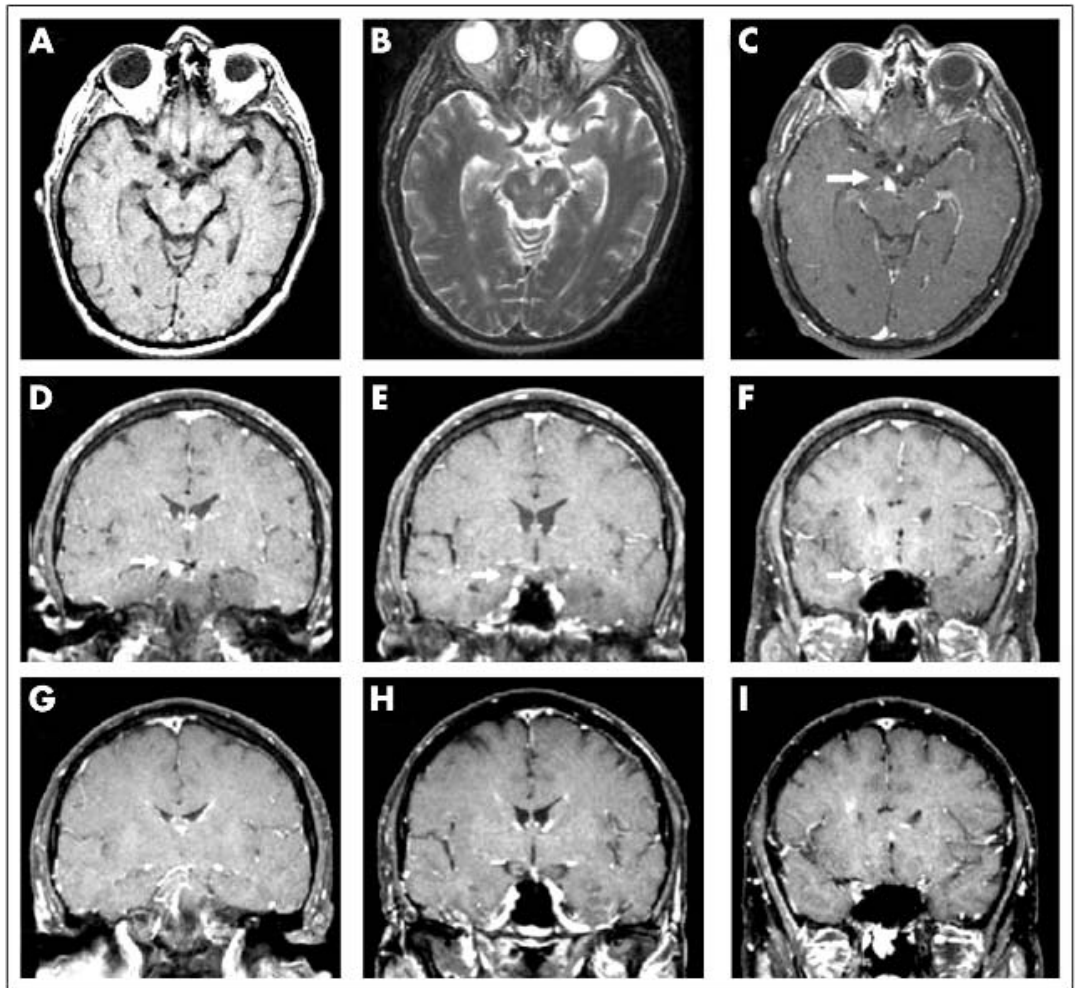

Figure 1 Head MRI showing the $8 \mathrm{~mm}$ (antero-posterior) $\times 6 \mathrm{~mm}$ (left to right) $\times 6 \mathrm{~mm}$ (rostrocaudal) tapering spheroid lesion at the base of the right midbrain, tracing the course of the oculomotor nerve forward into the cavernous sinus (panels A-F). The lesion is isointense to adjacent brain on $\mathrm{T} 1$ and $\mathrm{T} 2$ sequences (panels $\mathrm{A}$ and $\mathrm{B}$ ) and enhances on $\mathrm{A} \mathrm{T} 1$ sequence after gadolinium contrast (panel C). Pre-treatment (D-F) and post-treatment (G-I) coronal images demonstrate complete resolution at 7 months.

WBCs (97\% lymphocytes), protein of 86 $\mathrm{mg} \%$, and glucose of $71 \mathrm{mg} \%$. CSF VDRL and serum RPR titres were unchanged. At 6 months, no additional improvement in oculomotor nerve functions was seen but fatigue had subsided. Repeat MRI 7 months after hospital admission showed complete resolution of the oculomotor nerve abnormality.

\section{Discussion}

Neurosyphilis is known to cause oculomotor nerve palsies either in the meningovascular phase, due to small vessel vasculitis with resultant nerve infarction, ${ }^{2}$ or in granulomatous basal meningitis, due to inflammation of the nerve or its investiture; however, the literature on syphilitic mass lesions around the oculomotor nerve is sparse. Vogl et al reported a case of oculomotor nerve palsy associated with MR findings similar to ours that also resolved with penicillin treatment. Standaert et $a l^{4}$ described an enhancing penicillin-responsive lesion based in the interpeduncular cistern that compressed the ventral midbrain. The oculomotor nerve lesion in our patient was isointense to adjacent brain on $\mathrm{Tl}$ and $\mathrm{T} 2 \mathrm{MR}$ sequences, with brisk enhancement after intravenous injection of gadolinium contrast. We believe the lesion was a manifestation of meningeal syphilis in the form of an oculomotor nerve gumma. A gumma is a focally accentuated, exuberant granulomatous response of the meninges, typically with sparse treponemal organisms. Nonetheless, treatment of the underlying infection quiets the inflammatory process and can, as in our patient, lead to significant reversal of neurological deficit. We add our case to the growing literature on MR correlates of neurosyphilis and encourage a search for neurosyphilis when an unexplained mass lesion is present in the basal subarachnoid space. Neurosyphilis, albeit rare, still deserves inclusion among eminently treatable causes of a rapidly developing oculomotor nerve palsy.

W W Seeley, N Venna UCSF Memory and Aging Center, PO Box 1207, San Francisco, CA 94143-1207, USA

Correspondence to: W W Seeley, UCSF Memory and Aging Center, PO Box 1207, San Francisco, CA 94143-1207, USA; wseeley@memory.ucsf.edu

doi: 10.1136/jnnp.2003.025932

\section{References}

1 Stephenson J. Syphilis outbreak sparks concerns. JAMA 2003;289(8):974.

2 Holmes MD, Brant-Zawakzki MN, Simon RP. Clinical features of meningovascular syphilis. Neurology 1984;34:553-6.

3 Vogl T, Dresel S, Lochmuller H, et al. Third cranial nerve palsy caused by gummatous neurosyphilis: 1993;14(6):1329-31.

4 Standaert DG, Galetta SL, Atlas SW. Meningovascular syphilis with a gumma of the midbrain. J Clin Neuroophthalmol 1991;1 1(3):139-43.

High dose cyclophosphamide for

Myasthenia gravis (MG) exemplifies autoimmune disease. Most patients require immunomodulating treatment, including steroids, chemotherapy, or intravenous immunoglobulin (Ig), in addition to anticholinesterase MR findings. Am I Neuroradiol severe refractory myasthenia gravis 
treatment. Drachman et al ${ }^{1}$ published the beneficial effects of high dose cyclophosphamide in three patients with severe refractory myasthenia. We recount our experience of three myasthenic patients treated in a similar way.

\section{Materials and methods}

All patients participated in studies approved by the Drexel University College of Medicine and signed informed consent. These three patients with severe (class IVb) refractory MG includes all patients treated. Patients received cyclophosphamide $50 \mathrm{mg} / \mathrm{kg}$ (adjusted ideal body weight)/day over four consecutive days. Patients received antibacterial, antiviral, and antifungal prophylaxis. Haemorrhagic cystitis prophylaxis included Mesna and forced diuresis. Packed red cells and platelets were transfused to maintain haemoglobin $\geqslant 8.5 \mathrm{~g} / \mathrm{dL}$ and platelets $\geqslant 10 \times$ $10^{9} / \mathrm{L}$, respectively. Patients received filgrastim (G-CSF) (5 $\mu \mathrm{g} / \mathrm{kg} /$ day) starting day 10 until their absolute neutrophil count (ANC) reached $10 \times 10^{9} / \mathrm{L}$ for two consecutive days.

\section{Results}

Patient 1 was diagnosed with seronegative MG at 30 years of age by a positive tensilon test and a decremental response on repetitive stimulation. Initial treatment included pyridostigine and plasmapheresis, but worsening symptoms prompted thymectomies at 12 and 18 months later. Her thymic pathology revealed thymic hyperplasia. Additional treatment with only transient responses included low dose oral cyclophosphamide, intravenous Ig, azathioprine, methylprednisolone, and continued pyridostigine with plasmapheresis. She required 27 intubations between initial diagnosis and immunoablative treatment at 41 years of age.

Patient 2, previously reported, suffered from both seronegative $M G$ and chronic inflammatory demyelinating polyneuropathy (CIDP). ${ }^{2}$ He presented at 47 years of age with fluctuating double vision, ptosis, dysphagia, arm weakness, and breathing difficulties. Testing revealed a decremental response on repetitive stimulation. Pyridostigine was initiated. Thymectomy revealed a $75 \mathrm{~g}$ lipoma. His MG resulted in two intubations. After thymectomy, to control symptoms, prednisone (25-40 mg daily) was required. At 54 years of age, CIDP was diagnosed. Despite steroids (plasmapheresis, intravenous Ig, azathioprine, and pyridostigmine) he continued with symptoms of double vision, dysphonia, and dysphasia with a continued decremental response to repetitive stimulation. At 56 years of age, he underwent high dose cyclophosphamide without stem cell rescue.

Patient 3 was diagnosed with antibody positive MG at 12 years of age, initially treated with pyridostigine. She received her first thymectomy at age 18 years and continued on pyridostigine and occasional steroids. By 36 years of age, she was steroid dependent. Between ages 38 and 41 years she required 11 intubations and only transiently responded to intravenous Ig and plasmapheresis. A second thymectomy was performed at age 39 and cyclosporine (CsA) was initiated. She continued on prednisone $25 \mathrm{mg}$ qod, scheduled intravenous Ig every 3-4 weeks, and intermittent plasmapheresis. The CsA and Cellcept were maintained but poorly tolerated. At 41 years of age, she underwent high dose cyclophosphamide without stem cell rescue.

\section{Treatment course}

Patient 1 had 13 days of neutropenia, required three units of packed red cells and three platelet transfusions. Patient 2 had 9 days of neutropenia, required two units of packed red cells, and three platelet transfusions. Patient 3 had 11 days of neutropenia, required five units of packed red cells, and two platelet transfusions. Patients 1 and 3 experienced MG flares requiring intravenous Ig and plasmapheresis, but neither required intubation.

\section{Neurological follow up}

Patient 1 , intubated 27 times before treatment, required a single intubation during 48 months of follow up. To control less severe exacerbations, during the first 40 months after immunoablative treatment, oral cyclophosphamide was necessary. She continues scheduled plasmapheresis and pyridostigmine. No other immunomodulatory medications are prescribed.

Table 1 Patient characteristics before high dose cyclophosphamide treatmen

\begin{tabular}{|c|c|c|c|}
\hline Age/sex & Patient $141 /$ female & Patient $256 /$ male & Patient $341 /$ female \\
\hline Duration of MG $(y)$ & 11 & 9 & 29 \\
\hline MG severity class & $\mathrm{IVb}$ & $\mathrm{IVb}$ & $\mathrm{IVb}$ \\
\hline AChr antibody & Undetectable & Undetectable & Detectable \\
\hline Previous treatment & & & \\
\hline Pyridostigine & $\mathrm{x}$ & $\mathrm{x}$ & $\mathrm{x}$ \\
\hline Thymectomy(ies) & 2 & 1 & 2 \\
\hline $\begin{array}{l}\text { iv lg (no of } \\
\text { infusions) }\end{array}$ & 1 & 1 & 62 \\
\hline Prednisone & $\begin{array}{l}10-100 \mathrm{mg} \text { qd, duration } 3 \\
\text { years }\end{array}$ & $\begin{array}{l}40-100 \mathrm{mg} \mathrm{qd} \\
\text { duration } 7 \text { years }\end{array}$ & $\begin{array}{l}10-60 \mathrm{mg} \mathrm{qd} \text {, } \\
\text { duration } 4 \text { years }\end{array}$ \\
\hline $\begin{array}{l}\text { Plasmapheresis } \\
\text { (no. of procedures) }\end{array}$ & 217 & 14 & 16 \\
\hline Azathioprine & $\begin{array}{l}50 \mathrm{mg} / \mathrm{d} \text {, duration } 7 \text { months } \\
\text { limited by nausea/vomiting }\end{array}$ & $\begin{array}{l}200 \mathrm{mg} \text { qd, duration } 2 \\
\text { months limited by } \\
\text { nausea/vomiting }\end{array}$ & $\begin{array}{l}50-150 \mathrm{mg} \mathrm{qd}, \\
\text { duration } 15 \text { months }\end{array}$ \\
\hline $\begin{array}{l}\text { Oral } \\
\text { cyclophosphamide }\end{array}$ & $100 \mathrm{mg} \mathrm{qd}, 28$ months & & \\
\hline Cyclosporine & & & $\begin{array}{l}50-125 \mathrm{mg} \mathrm{bid} \\
\text { duration } 39 \text { months }\end{array}$ \\
\hline Cellcept & & & $\begin{array}{l}250-500 \mathrm{mg} \mathrm{qd} \text {, } \\
\text { duration } 7 \text { months }\end{array}$ \\
\hline
\end{tabular}

MG, myasthenia gravis; iv, intravenous; Ig, immunoglobulin; qd, four times daily; bid, twice daily
Patient 2 had myasthenic symptoms of dysphagia and diplopia. Seven months after treatment pyridostigmine was stopped and after 12 months prednisone was stopped. Twenty five months after treatment, his MG is in full remission.

Patient 3 experienced five flares at 1, 6, 11, 19 , and 30 weeks following treatment. The exacerbations at 1,6 , and 11 weeks required intravenous Ig and steroids; exacerbations at 1,19 , and 30 weeks required plasmapheresis. Her last exacerbation necessitated intubation. Between exacerbations her functional ability consistently improved. She stopped steroids at 50 weeks. At 52 weeks, a slow pyridostigine taper began. Her serum AChr levels did not correlate with disease activity during the follow up periods.

\section{Discussion}

The patients discussed have all suffered from severe refractory MG, which requires multiple intubations. All underwent thymectomy: patients 1 and 3 repeat thymectomies. Patient 2 had an early and sustained response to treatment. Patients 1 and 3 had multiple exacerbations. As this treatment targets IgG production, exacerbations following treatment are expected. Patient 1 , who required 27 intubations before treatment and only once since, and who has in the past 6 months stopped oral cyclophosphamide, may yet to enjoy the maximum benefit of this treatment. Patient 3 , one year after treatment, has an improving activity level. The intervals between exacerbations are increasing: 5, 8, and 11 weeks. It is 26 weeks since her last exacerbation. Recently, Drachman et al published a single institution case series of three patients with refractory MG who were also treated with high dose cyclophosphamide. In this series, one patient had AChR antibody negative MuSK antibody positive myasthenia. Their mean disease duration was 10.3 (range: 3-15) years; one required intubation and median follow up was 24 (range: 7-40) months. In comparison, in the three patients described here, two had antibody negative myasthenia and the mean disease duration was 16.3 (range: 9-29) years. All required multiple intubations: 27, 2, and 11 , and our median follow up is 25 (range: 13-48) months. During follow up, patient 3's serum AChr levels remained detectable and did not correlate with her clinical course. Drachman et al reported a decline in antibody levels in their patients treated in a similar way, although AChr antibody titres and MuSK antibodies persisted in their patients even after 2 years. ${ }^{1}$ This suggests that long term remissions in MG may be possible even without achieving complete immunoablation. High dose cyclophosphamide has the potential to significantly reduce symptoms and increase life quality among people with MG refractory compared to conventional treatment. Long term follow up is necessary to evaluate the duration effect and time to maximum benefit. High dose cyclophosphamide treatment warrants further study as a treatment for severe refractory MG.

D E Gladstone

Stony Brook University, Health Sciences Center, Division of Oncology, New York, USA

T H Brannagan III

Weill Medical College of Cornell University, New York, USA

R J Schwartzman, A A Prestrud, I Brodsky Drexel University College of Medicine, Philadelphia, USA 
Correspondence to: Dr D E Gladstone, Stony Brook University, Health Sciences Center, Division of Oncology, T17-080, Stony Brook, NY 11794, USA dsgladstone@comcast.net

doi: 10.1136/jnnp.2003.019232

\section{References}

1 Drachman DB, Jones RJ, Brodsky RA. Treatment of refractory myasthenia: "rebooting" with highdose cyclophosphamide. Ann Neuro 2003;53(1):29-34.

2 Brannagan TH III, Pradhan A, HeimanPatterson T, et al. High-dose cyclophosphamide without stem-cell rescue for refractory CIDP. Neurology 2002;58(12):1856-8.

\section{Acute head drop after cervical hyperflexion injury}

Head drop is familiar to neurologists, but not widely appreciated by neurosurgeons. There are multiple causes of this condition ${ }^{1}$ in which the patient is unable to hold their head up because of weakness of the neck extensor musculature. It predominantly results from primary muscle pathologies in the neck extensor muscles, with occasional evidence supporting a neurogenic aetiology. ${ }^{12}$ I describe three patients in whom acute head drop closely followed cervical hyperflexion injury, and suggest that the cause is bilateral traction neurapraxia of one or more cervical dorsal rami.

Patient A was an 84 year old man who enjoyed excellent health prior to falling backwards, striking his occiput on a wall and sustaining forced flexion of the cervical spine. He complained of posterior cervical pain but, when seen in casualty for closure of an occipital laceration, was found to be neurologically intact. Cervical $x$ rays showed only degenerative disease in the mid-lower cervical spine and loss of lordosis. Over 2 weeks the pain in his neck resolved, but he became aware of a difficulty holding his head up as the day progressed and, later, of aching in his neck extensor muscles. He was referred to neurosurgery as a possible case of delayed instability. Cervical $x$ rays demonstrated $5^{\circ}$ of forward angulation at $\mathrm{C} 4 / \mathrm{C} 5$, which did not change with neck flexion, but were otherwise unchanged. He remained neurologically intact but, fearing progression of the angulation and development of neural injury, posterior segmental fixation at C4/5 with a Hartshill rectangle and sublaminar wiring was advised. Surgery was remarkable only for the absence of significant ligamentous injury or abnormal mobility. Unfortunately, his head ptosis recurred after 2 months. $x$ Rays showed that the sublaminar wires at $\mathrm{C} 5$ had "cheese-wired" through the bone and allowed recurrence of angulation. He remained neurologically intact. After some discussion, he submitted to extended fixation from C3-C7, producing good alignment, albeit with restricted neck movements. However, he had ongoing problems with neck pain because of prominence of the metalwork due to profound atrophy of the paraspinal muscles. Three months later, he again developed head drop because of "cheesewiring", and the Hartshill rectangle was eroding through the skin, necessitating a third procedure to remove it. At this stage, a muscle biopsy was performed showing end-stage atrophy and fibrosis although no comment could be made as to aetiology. The patient declined further investigation or surgery and was managed in a Philadelphia collar in the long term. Despite all the above, the malalignment at C4/5 never progressed, nor did any neurological deficits develop.

Patient B was a fit 72 year old man who sustained a flexion/extension whiplash injury during a road traffic accident (RTA). In casualty, he had minor neck pain but was neurologically intact and had cervical $x$ rays showing only minor degenerative changes and loss of lordosis. He was managed with analgesics and a rigid collar. Ten days later he returned to casualty complaining of aching in his neck and progressive difficulty in holding up his head throughout the day. Neurological examination remained normal. Cervical $x$ rays showed angulation into $7^{\circ}$ of flexion at $\mathrm{C} 5 / 6$, but were otherwise unchanged. He was referred to neurosurgery and at review was strikingly reminiscent of patient A. He had to hold his chin up with a hand to look ahead, had pain in the back of his neck, which developed over the day unless he used his collar, and was neurologically normal, including in the cervical dermatomes. Magnetic resonance imaging (MRI) of his neck revealed normal soft tissue anatomy. A neurological opinion confirmed the normal examination, other than head ptosis. There was no evidence of inflammatory, autoimmune, or endocrine disease clinically or biochemically, the Tensilon test was negative, and serum creatine kinase was normal. There were no features of Parkinson's disease or amyotrophic lateral sclerosis (ALS). Electroneuromyography (EMG) studies of the neck muscles performed 3 weeks after injury were normal in the ventral muscles, but there were typical features of acute partial denervation in the neck extensors bilaterally, particularly in a band in the midto-low cervical spine with more normal EMGs above and below this. However, electrophysiological examination of the limbs was abnormal also and consistent with an asymptomatic peripheral neuropathy. The patient declined muscle or nerve biopsy.

In view of patient $\mathrm{A}^{\prime}$ s course and the evidence in patient $\mathrm{B}$ of acute denervation that might recover, patient $\mathrm{B}$ was managed expectantly. Physiotherapy was used to maintain range of neck movement and encourage use of the neck extensor muscles. He was given a Philadelphia collar, which was worn by day once he became aware of head ptosis. With this regime he recovered to normal over 4 months, including recovery of the spinal alignment at $\mathrm{C} 5 / 6$, and the Philadelphia collar was withdrawn. There has been no recurrence of head ptosis.

Patient C, a 54 year old man, was similar to patient B. He suffered a whiplash injury in an RTA and developed head ptosis and angulation at C5/6 on cervical $x$ rays 2 weeks later. Investigation and management mirrored patient B. He also had focal abnormality of his neck extensor muscle EMG, which suggests partial denervation, but otherwise was normal clinically, biochemically, and electrophysiologically. We did not suggest muscle or nerve biopsy as it was clear he would be managed conservatively. With physiotherapy and external bracing, patient $C$ made a complete recovery in 2 months, including recovery of spinal alignment at C5/6. There was no recurrence of head ptosis at last contact.

Although there are reports of head drop in conditions predominantly affecting neural rather than muscular elements, ${ }^{3}$ Umapathi et $a l^{1}$ cite Braun et al, ${ }^{4}$ who treat refractory torticollis by section of multiple cervical dorsal rami without generating significant functional deficits, as evidence that focal denervation of neck extensor muscles is unlikely to cause head ptosis. This surgical denervation, however, is unilateral and the denervated muscles are also likely to be grossly abnormal because of secondary changes resulting from the underlying condition. The cat neck extensor muscle biventer cervicis (analogous to human semispinalis capitis) has tendinous inscriptions defining serially arranged compartments, each receiving segmental innervation from a cervical dorsal ramus. The muscle only generates useful tension if all compartments are co-stimulated; unstimulated compartments act as weak springs in series and dissipate tension within the muscle. ${ }^{5}$ There is some evidence for similar architecture in human neck extensors: they receive innervation from several cervical dorsal $\mathrm{rami}^{6}$ and have tendinous inscriptions producing several at least partially serial compartments. ${ }^{7}$ Denervation of one compartment bilaterally would produce significant weakness and fatigability in such compartmentalised muscles. Additionally, the deeper muscles only traverse one motion segment and are innervated by one posterior primary ramus. Segmental denervation of either type of muscle would lead to angulation at a motion segment, limited in degree by intact joints, ligaments, and disc space.

Whiplash injury can cause neurapraxia of cranial nerve XI, ${ }^{8}$ XII, ${ }^{9}$ and branches of the cervical plexus, ${ }^{10}$ and there are other reports of traction neuropathies in the neck. ${ }^{11}{ }^{12}$ In the present cases, the close temporal relationship of the head drop to a forced flexion injury and the EMG findings suggesting acute denervation of neck extensor muscles are consistent with a neurogenic mechanism. Although dystonia of neck flexor muscles can produce head drop, these patients could easily lift their chins and there was no evidence of ventral muscle hypertonia on clinical examination. In addition, in patients $\mathrm{B}$ and $\mathrm{C}$, there were normal EMG findings in the ventral neck muscles but abnormal findings in the neck extensors.

Neurapraxia of dorsal primary rami would be expected to recover in time, as happened in patients B and C. Equally, muscle tearing would recover in time, but it is inconceivable that sufficient fibres would have been torn to produce head drop without also producing soft tissue abnormalities on MRI scanning. This is not the case. Only two of the cases were investigated to exclude primary neuromuscular disorders. These were excluded in patient C. Although patient B had evidence of a pre-existing peripheral neuropathy, this may simply have made him more prone to traction neurapraxia after whiplash and his eventual recovery is consistent with the proposed mechanism.

It is unclear why this syndrome has not been described before. Perhaps most whiplash injuries produce insufficient neurapraxia to provoke head drop unless patient factors adversely affect the transmission of forces to the nerves or their susceptibility to injury. In non-predisposed individuals, sufficiently severe injuries might instead produce fractures/dislocations, whose management masks signs of a concomitant neurapraxia. Lesser injuries might produce mild head drop, which is either not recognised or recovers quickly and never requires secondary referral. Furthermore, although motor deficits may be rare after whiplash, sensory symptoms may be common, presenting as the patient's symptoms in a case of "typical" whiplash syndrome. There is support for this 
notion from reports of symptomatic relief after cervical nerve blocks in cases of "third occipital nerve headache" and other postwhiplash syndromes. ${ }^{13} 14$

Finally, Umapathi et $a l^{1}$ suggest that cervical spinal fusion might be useful in optimising head position for patients with head drop. I would caution against this approach, given our experience with patient A, although alternative fixation methods, such as lateral mass plating, with careful attention paid to achieving bony fusion, might be appropriate on occasion if conservative measures have failed.

\section{Acknowledgements}

I would like to acknowledge the contribution of the neurophysiologists involved in these cases, particularly Dr Roger Cull, Consultant Neurophysiologist, Department of Clinical Neurosciences, Western General Hospital, Edinburgh, UK.

R F Price

Department of Neurosurgery, Royal Adelaide Hospital, North Terrace, Adelaide SA5000, Australia; Rupert_price@hotmail.com

doi: 10.1136/jnnp.2003.006429

\section{References}

1 Umapathi T, Chaudhry V, Cornblath D, et al. Head drop and camptocormia. J Neurol Neurosurg Psychiatry 2002;73:1-7.

2 Chaouat D, Belange G. Dropped head syndrome. Three case reports. Rev Rhum Engl Ed 1999:66:430-3.

3 Hoffman D, Gutmann L. The dropped head syndrome with chronic inflammatory demyelinating polyneuropathy. Muscle Nerve 1994;17:808-10.

4 Braun V, Mayer M, Antoniadis G, et al. Reconstruction of the spinal accessory nerve with an anastomosis to the dorsal C3 branch: technical note. Neurosurgery 1996;38:208-10.

5 Price RF. The use of Succinylcholine in the identification and characterisation of afferent axons from tandem muscle spindles. PhD Thesis, Edinburgh University, 1991.

6 Bogduk N. The clinical anatomy of the cervical dorsal rami. Spine 1982;7:319-30.

7 Kamibayashi LK, Richmond FJ. Morphometry of human neck muscles. Spine 1998;23:1314-23.

8 Bodack MP, Tunkel RS, Marini SG, et al. Spinal accessory nerve palsy as a cause of pain after whiplash injury. J Pain Symptom Manage 1998;15:321-8.

9 Clavier E, Thiebolt J, Hannequin D, et al. Cervicooccipital injury and bilateral paralysis of cranial nerve XII. Apropos of a case. J Radiol 1986:67:3235-35.

10 Tosi L, Zanetta G. Trapezius muscle atrophy after whiplash injury: accessory nerve injury or cervical plexus injury? I Neurol Neurosurg Psychiatry 1991;54:561.

11 Narakas AO. Injuries of the brachial plexus and neighbouring peripheral nerves in vertebral fractures and other trauma of the cervical spine. Orthopade 1987;16:81-6.

12 Ginsburg GM, Bassett GS. Hypoglossal nerve injury caused by halo-suspension traction. A case report. Spine 1998;23:1490-3.

13 Lord SM, Barnsley L, Wallis BJ, et al. Third occipital nerve headache: a prevalence study. J Neurol Neurosurg Psychiatry 1994:57:1187-90.

14 Bovin G, Berg R, Dale LG. Cervicogenic headache: anaesthetic blockade of cervical nerves (C2-C5) and facet joint (C2/C3). Pain 1992;49:315-20.

\section{Acute disseminated encephalomyelitis temporally associated with Campylobacter gastroenteritis}

The association of Campylobacter infection and Guillain-Barré syndrome is well recognised.
We report a case of acute disseminated encephalomyelitis (ADEM) temporally associated with Campylobacter gastroenteritis in a previously fit man. A MedLine search using the keywords "ADEM", "demyelination" and "campylobacter" revealed no previous reports of ADEM associated with Campylobacter infection in isolation.

A 24 year old man presented to his general practitioner with a 4 day history of nonbloody diarrhoea associated with fevers and sweats. His past medical history was unremarkable. He drank 6 units of alcohol per week and smoked only occasionally. His general practitioner prescribed loperamide for symptomatic relief. Campylobacter species was later isolated from stool samples. By day 5 of his illness, his diarrhoea had settled and he had become constipated. However, he remained febrile and developed nausea and vomiting. His general practitioner prescribed erythromycin but he tolerated only two doses because of nausea.

Fourteen days into the illness he was admitted to hospital complaining of headache, fever, and sweats. Examination revealed a temperature of $38.4^{\circ} \mathrm{C}$, pulse of 65 beats/min and normal blood pressure. Rectal examination revealed hard stool. There were no focal neurological signs. His haemoglobin was $15.3 \mathrm{~g} / \mathrm{dl}$, leukocyte count was $13.3 \times 10^{9} / 1(87.1 \%$ neutrophils) and C-reactive protein was $12.8 \mathrm{mg} / \mathrm{l}$. Two days after admission (day 16 of illness), his family reported a change in his personality and he complained of slurring of speech, intermittent diplopia, and difficulty in walking. Examination revealed mild dysarthria, left sided facial weakness, mild left pyramidal limb weakness, and decreased sensation in the left leg. Tendon reflexes were brisk but plantar responses were flexor. His gait was ataxic. Cranial CT scan showed no significant abnormalities. Lumbar puncture revealed an opening pressure of $160 \mathrm{~mm} \mathrm{CSF}$, total cell count of $34 / \mathrm{mm}^{3}$ with a white cell count of $20 / \mathrm{mm}^{3}$ (100\% lymphocytes), total protein of $541 \mathrm{mg} /$, glucose of $3.2 \mathrm{mmol} / \mathrm{l}$, and negative oligoclonal banding. No organisms were seen and PCR was negative for enteroviruses and herpes virus. An EEG showed mild excess of generalised slow wave activity. Cranial MRI scan was performed on a $1.5 \mathrm{~T}$ Siemens magnetic system. T2 weighted imaging of the brain showed multiple high signal foci in the supra- and infra-tentorial compartments involving the cortex, white matter, and deep grey matter. One lesion in the right peri-trigonal white matter showed slight enhancement following intravenous gadolinium diethylene-triaminopenta-acetic acid (gadolinium DTPA) injection (fig 1). The abnormalities were consistent with ADEM.

The patient was initially treated with aciclovir $10 \mathrm{mg} / \mathrm{kg}$ three times daily, ampicillin $2 \mathrm{~g}$ four times daily and ciprofloxacin $500 \mathrm{mg}$ twice daily, but was subsequently given intravenous methylprednisolone $1 \mathrm{~g}$ daily for 3 days after the diagnosis of ADEM was made. Aciclovir and ampicillin were discontinued when the negative laboratory results were available but ciprofloxacin was continued for 7 days. One day after treatment with methylprednisolone he noticed an improvement in his speech and gait, and after 7 days of starting treatment he had no ataxia and was discharged home. He appeared to have made a full recovery when he was reviewed at 6 weeks and has since remained asymptomatic.

ADEM is an acute monophasic immune mediated inflammatory demyelinating disease of the central nervous system. It is an uncommon but a serious condition with mortality rates estimated between $10-30 \%$. In the majority of cases, the condition develops after systemic viral infections most commonly measles, mumps, rubella, influenza A and B, herpes simplex, Epstein-Barr virus, varicella, and vaccinia. ${ }^{2}$ It has also been reported following bacterial infections with Mycoplasma pneumoniae, Chlamydia, Legionella, and Streptococcus, or following immunisations for rabies, diphtheria/tetanus/pertussis, smallpox, measles and Japanese B encephalitis. The pathogenesis of ADEM remains poorly understood. However, the evidence suggests that activated $\mathrm{T}$ cells, which recognise amino acid sequences shared between microbial epitopes and myelin antigens, attack central nervous system structures alone or in synergy with antibodies. ${ }^{3}$ Viral or bacterial superantigens could likewise trigger autoactive $\mathrm{T}$ cells with similar results.

The diagnosis of ADEM is usually made clinically with the aid of MRI scanning, lumbar puncture finding and electrophysiology studies. MRI scanning reveals multiple areas of increased signal on $\mathrm{T} 2$ weighted images in the white matter throughout the central nervous system, most being located in the subcortical white matter of both hemispheres, which are often quite extensive and enhance with contrast. CSF findings include mononuclear pleocytosis and mild protein elevation. There are few data available on evidence based treatment regimens, but treatment is usually instituted with high dose glucocorticoids. Plasmapheresis and intravenous immunoglobulin have also been used.

Campylobacter gastroenteritis is the most common cause of acute gastroenteritis in the UK, accounting for over 56000 cases in 2000. Its incidence has risen progressively over the past 2 decades. In the majority of cases, the illness self terminates within a few days with no long term consequences. It is estimated that approximately $\mathrm{l} / 1000$ reported campylobacteriosis cases leads to Guillain-Barré syndrome, and around $33 \%$ of GuillainBarré syndrome cases in the western world may be triggered by campylobacteriosis. Huber et al reported a case of combined ADEM and acute motor axonal neuropathy following Campylobacter jejuni infection and hepatitis A immunisation. ${ }^{4}$ Cranial MRI scanning showed a slight enhancement in the left cerebral peduncle that disappeared when the study was repeated a week later. Nasralla et al reported a case of postinfectious encephalomyelitis in a young child following Campylobacter jejuni enteritis." Cranial MRI scanning showed a combination of predominant grey matter involvement with concomitant focal areas of subcortical white matter lesions with no parenchymal enhancement, which the authors felt to be different from the pattern of signal abnormalities seen in patients with ADEM. The MRI abnormalities in our case were in keeping with ADEM although, as with the case reported by Huber et al, the amount of enhancement was minimal, indicating that the majority of the lesions were not acute. ${ }^{6}$ The paucity of reported cases of ADEM following Campylobacter infection is surprising given the strong association between Campylobacter jejuni infection and Guillain-Barré syndrome and the pathogenesis of the latter. In these cases, Campylobacter jejuni induces humeral and cellular immune responses due to molecular mimicry between specific lipopolysaccaride epitopes on the infecting agent and target epitopes on the 

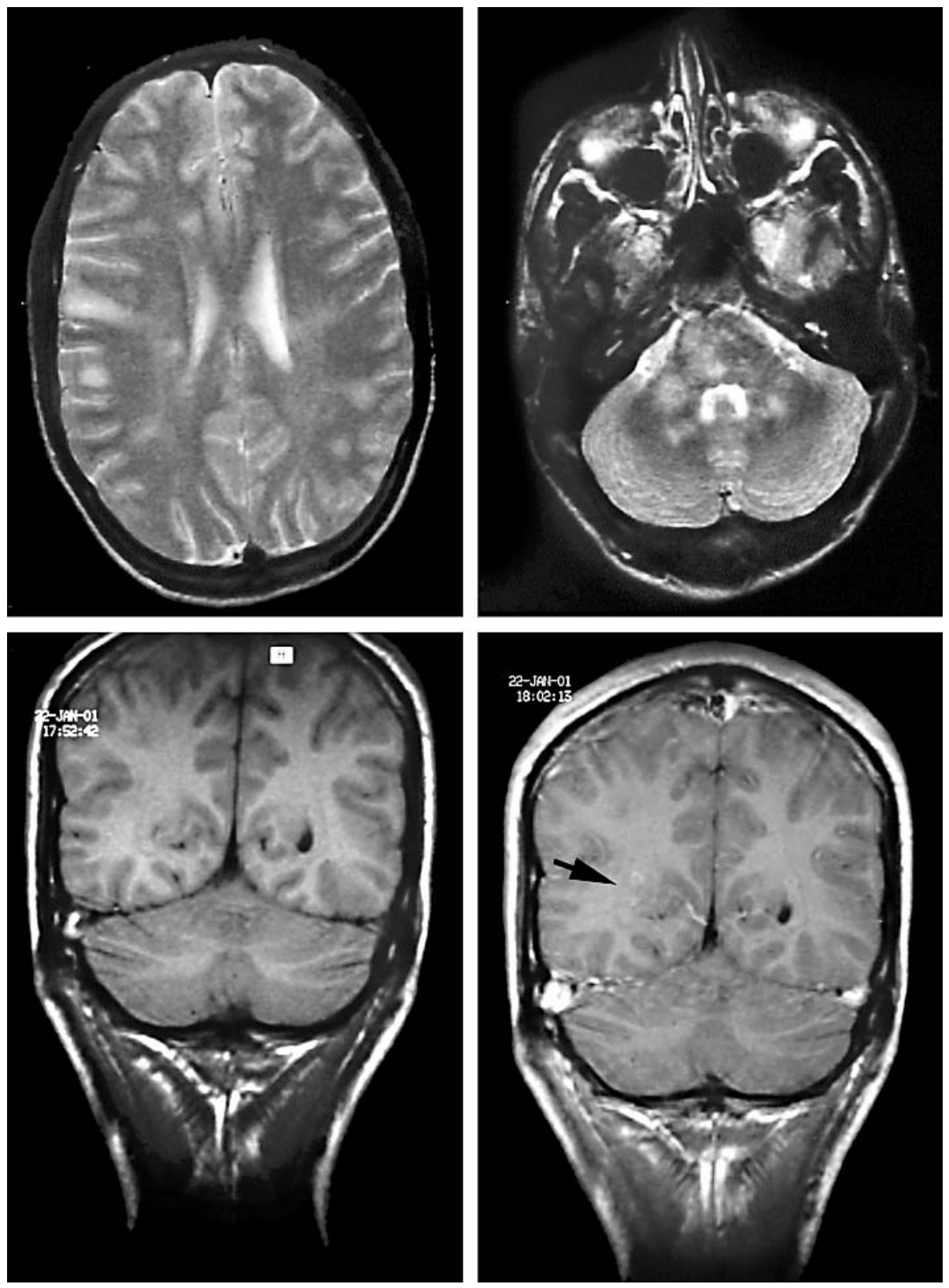

Figure 1 Axial T2 weighted image showing supra- and infra-tentorial high signals in both hemispheres, and coronal $\mathrm{T} 1$ weighted images showing peri-trigonal white matter lesions with slight enhancement following intravenous gadolinium DTPA injection in keeping with ADEM.

surface components of the peripheral nerves, resulting is myelin destruction and axonal degeneration. ${ }^{7}$ Furthermore, patients with ADEM often have peripheral nervous system involvement and there have been occasional cases of ADEM associated with GuillainBarré syndrome. Our patient did not have any clinical features suggestive of peripheral nervous system involvement. However, nerve conduction studies were not performed and a degree of sub-clinical neuropathy cannot therefore be excluded.

We describe the first identifiable case of ADEM temporally associated with Campylobacter gastroenteritis alone. Our patient made an excellent recovery associated with therapy with high dose methylprednisolone.

\section{Acknowledgements}

We are most grateful to Dr D Connolly for reviewing the MRI imaging.
D Orr, M W McKendrick Department of Infection and Tropical Medicine Royal Hallamshire Hospital, Sheffield, UK

B Sharrack

Department of Neurology, Royal Hallamshire Hospital, Sheffield, UK

doi: 10.1136/jnnp.2003.013433

Competing interests: none declared

Received 26 February 2003 Revised 14 July 2003 Accepted 19 August 2003

\section{References}

1 Kennard C, Swash M. Acute viral encephalitis. Its diagnosis and outcome. Brain

1981;104:129-48.
2 Tselis AC, Lisak RP. Acute disseminated encephalomyelitis. In: Antel J, Birnbaum G Hartung HP, eds. Clinical neuroimmunology Boston: Blackwell Science, 1998; 1 16-47.

3 Hartung HP, Crossman RI. ADEM: distinct disease or part of the MS spectrum? Neurology 2001:56:1257-60.

4 Huber S, Kappos L, Fuhr P, et al. Combined acute disseminated encephalomyelitis and acute motor axonal neuropathy after vaccination for hepatitis A and infection with Campylobaccter jejuni. J Neurol 1999;246:1204-6.

5 Nasralla CA, Pay N, Goodpasture HC, et al. Postinfectious encephalopathy in a child following Campylobacter jejuni enteritis. Am J Neuroradio 1993; 14:444-8.

6 Singh S, Alexander M, Korah IP. Acute disseminated encephalomyelitis: MR imaging features. Am J Roentgenol 1999; 173:1101-7.

7 Hughes RA, Hadden RD, Gregson NA, et al. Pathogenesis of Guillain-Barre syndrome. J Neuroimmunol 1999;100: 74-97. 


\section{PostScript}

\section{CORRESPONDENCE}

\section{Evidence for an association between the CSF HVA:5-HIAA ratio and aggressiveness in frontotemporal dementia but not in Alzheimer's disease}

In their recent paper, Soderstrom et al confirmed their preliminary data suggesting that the CSF HVA:5-HIAA ratio was associated with psychopathic traits and, in particular, violent and aggressive behaviour with childhood onset and adult expression. These findings might indeed reflect changed dopaminergic activity, possibly as a result of serotonergic dysregulation. We hypothesise that their findings might be applicable to other brain disorders characterised by specific behavioural disturbances, including aggression and agitation. Indeed, since several studies have found associations between altered serotonergic neurotransmission and aggression in persons with dementia, ${ }^{23}$ we could propose that the CSF HVA:5-HIAA ratio might be associated with aggression in persons with dementia as well. To test this hypothesis, we performed an interim analysis on 102 out of 302 patients who were included in a prospective and longitudinal study on neurochemical and genetic correlates of behavioural and psychological signs and symptoms of dementia (BPSD). The data presented further support a general application of the interesting findings of Soderstrom et al. ${ }^{1}$

Patients with various neurodegenerative forms of dementia were included in this prospective study, and were followed up by means of a neuropsychological and behavioural assessment every six months. In any case of death, brain autopsy was performed for neurochemical analysis as well as for neuropathological confirmation of the clinical diagnosis. All subjects and their caregivers gave informed consent to participation in the study, which was approved by the local ethics committee.

At baseline, behaviour was assessed by means of a battery of behavioural assessment scales which included the Behavioural Pathology in Alzheimer's Disease Rating Scale (Behave-AD) and the Cohen-Mansfield Agitation Inventory (CMAI). Lumbar puncture was performed between 9 and 10 am following overnight bed rest and fasting. The first $11 \mathrm{ml}$ of CSF were collected in several polypropylene vials that were immediately frozen in liquid nitrogen and stored at $-80^{\circ} \mathrm{C}$. Neurochemical analysis was carried out on the CSF fraction containing 6-7.5 $\mathrm{ml}$ by means of high performance liquid chromatography and electrochemical detection according to a modification of a recently described method. ${ }^{4}$ Routine investigation of the CSF included cell count, total protein and glucose analysis, and agar gel electrophoresis of proteins

For this interim analysis, HVA and 5-HIIA levels were determined in the CSF of 13 participants with frontotemporal lobe dementia (FTD) and 89 participants with probable Alzheimer's disease (AD). Spearman Rank
Order was used for correlation analysis between the CSF HVA:5-HIAA ratio and BPSD, applying SigmaStat Software (SPSS Science, Erkrath, Germany).

In the $\mathrm{AD}$ patient group, no significant correlations were found between the CSF HVA:5-HIAA ratio and Behave-AD clusters, total and global scores, or CMAI clusters (aggressive, physically non-aggressive, and verbally agitated behaviours) and total scores. In persons with FTD, however, the CSF HVA:5-HIAA ratio correlated significantly with the Behave-AD aggressiveness cluster score $(r=0.586 ; \mathrm{p}=0.033)$ and with the CMAI verbally agitated behaviour cluster score $(r=0.564 ; \mathrm{p}=0.041)$. Despite small sample sizes, effects of treatments were ruled out by comparing the CSF levels of HVA $(t$ test: $\mathrm{p}=0.691), 5$-HIAA $(\mathrm{p}=0.370)$, and the CSF HVA:5-HIAA ratio $(\mathrm{p}=0.157)$ between six untreated subjects with FTD and seven subjects with FTD who were receiving atypical antipsychotics.

Our preliminary results revealed an association between aggression and the CSF HVA:5-HIAA ratio in participants with FTD but not in those with $\mathrm{AD}$. More refined neurochemical analyses, including the determination of all catecholamines and serotonin in an extended population of FTD patients, are scheduled. These will allow further testing of the hypothesis that altered serotonergic modulation of dopaminergic neurotransmission leads to BPSD and in particular to aggression. Meanwhile, our findings suggest that the association between the CSF HVA:5-HIAA ratio and aggression as observed by Soderstrom et al ${ }^{1}$ is not limited to violent and aggressive behaviour with childhood onset and adult expression, but may indicate an underlying pathophysiological mechanism that may be common to aggressive symptomatology in other brain disorders, such as frontotemporal lobe dementia.

S Engelborghs, E Vloeberghs, K Maertens, B Marescau, P P De Deyn

Laboratory of Neurochemistry and Behaviour, BornBunge Foundation, University of Antwerp, Belgium

S Engelborghs, P P De Deyn

Department of Neurology, Middelheim General Hospital, Antwerp, Belgium

Correspondence to: Professor P P De Deyn; peter.dedeyn@ua.ac.be

\section{References}

1 Soderstrom H, Blennow K, Sjodin A-K, et al. New evidence for an association between the CSF HVA:5-HIAA ratio and psychopathic traits. J Neurol Neurosurg Psychiatry 2003;74:918-21.

2 Lai MKP, Tsang SWY, Francis PT, et al. Reduced $5-\mathrm{HT}_{1 \mathrm{~A}}$ receptor binding in the temporal cortex correlates with aggressive behavior in Alzheimer disease. Brain Res 2003;974:82-7.

3 Sukonick DL, Pollock BG, Sweet RA, et al. The 5 -HTTPR*S/*L polymorphism and aggressive behavior in Alzheimer disease. Arch Neurol 2001;58:1425-8.

4 Engelborghs S, Marescau B, De Deyn PP. Amino acids and biogenic amines in cerebrospinal fluid of patients with Parkinson's disease. Neurochem Res 2003;28:1145-50

\section{Extensive radiculopathy: another false localising sign in intracranial hypertension}

We read with interest the review by Larner on false localising signs. Among the various false localising signs described in patients with intracranial hypertension (ICHT), radiculopathy is an important manifestation which is probably under recognised. Many authors have documented subtle features of radiculopathy in patients with isolated intracranial hypertension (IIH). The usual manifestations of radiculopathy in these cases were acral paraesthesias, ${ }^{2}$ and backache and radicular pain. ${ }^{34}$ Rarely, motor deficits due to radiculopathy caused by ICHT have been described. ${ }^{56}$

Obeid et al reported two patients with extensive radiculopathy due to $\mathrm{ICHT}^{5}$; one individual had IIH and the other had cerebral sinus venous thrombosis. Both persons had papilloedema, marked visual impairment, and flaccid areflexic quadriparesis with normal MRI of brain, brainstem, and cervical spinal cord. The electrophysiological findings were consistent with radiculopathy. Both individuals initially received intravenous immunoglobulin for Guillain-Barré syndrome, without benefit, but they responded well to lumboperitoneal shunting. We also encountered two such cases with angiographically proven cerebral venous sinus thrombosis. ${ }^{6}$

The most likely mechanism at the basis of radiculopathy appears to be similar to that of other cranial neuropathies in ICHT-that is, mechanical compression of nerve roots, due to elevated CSF pressure distending the subarachnoid space. Documented enlargement of spinal subarachnoid space and distended root pouches in a patient with radicular pain and areflexia due to IIH supports this view. ${ }^{3}$ Radiculopathy secondary to ICHT has been reported almost exclusively in patients with IIH or cerebral venous sinus thrombosis.

Other causes of ICHT may not induce a diffuse increase in pressure in both intracranial and intraspinal compartments, and are unlikely to manifest as radiculopathy. The constellation of flaccid-areflexic quadriplegia and papilloedema may be misdiagnosed as Guillain-Barré syndrome with papilloedema. Careful analysis of the evolution of symptoms, estimation of CSF pressure, and appropriate vascular imaging should help to correctly identify the cause of ICHT.

A Moosa, M A Joy, A Kumar

Department of Neurology, Amrita Institute of Medical Sciences and Research Center, Cochin, Kerala, India

\section{Correspondence to: $\operatorname{Dr} \mathrm{N}$ V A Moosa;} ahsanmoosa@yahoo.com

\section{References}

1 Larner AJ. False localising signs. J Neuro Neurosurg Psychiatry 2003:74:415-18.

2 Round R, Keane JR. The minor symptoms of increased intracranial pressure: 101 patients with benign intracranial hypertension. Neurology 1988;38:1461-4.

3 Bortoluzzi M, Di Lauro L, Marini G. Benign intracranial hypertension with spinal and radicular pain. J Neurosurg 1982;57:833-6. 
4 Santinelli R, Tolone C, Toraldo R, et al. Familial idiopathic intracranial hypertension with spinal and radicular pain. Arch Neurol 1998;55:854-6.

5 Obeid T, Awada A, Mousali Y, et al. Extensive radiculopathy: a manifestation of intracranial hypertension. Eur I Neurol 2000;7:549-53.

6 Moosa A, Kishore A, Gupta AK, et al. Blindness, ophthalmoplegia and extensive radiculopathy-an unusual clinical syndrome in intracranial sinovenous thrombosis. Neurol India (in press).

\section{Role of entacapone in later Parkinson's disease not yet established}

The study by Brooks and Sagar, ${ }^{1}$ along with a number of previous others, demonstrates benefit for the catechol-O-methyltransferase (COMT) inhibitor entacapone when compared with placebo in Parkinson's disease (PD). However, this is insufficient evidence to justify the authors' conclusion that "it appears logical to employ levodopa combined with entacapone routinely". The important issue is not whether entacapone is more efficacious than placebo, but whether it is more or less clinically effective and cost effective than the other available treatments for patients with PD that is no longer adequately controlled by levodopa alone. Other available agents-including dopamine agonists and monoamine oxidase type $\mathrm{B}$ (MAOB) inhibitors-have also shown efficacy when compared with placebo. The paper would have benefited from a balanced discussion of the merits of entacapone compared with these other available treatment options.

Such a discussion is likely to have been inconclusive, however, as there is a dearth of reliable evidence on the best treatment for $\mathrm{PD}$, at any stage of the disease, since very few trials directly comparing active treatments have been undertaken. ${ }^{2}$ Companies are reluctant to undertake such trials, as it is not in their commercial interests to risk studies that might show their product to be inferior to that of a competitor. For this reason, independently funded trials-such as the current PD MED trial in the UK ${ }^{3}$ - should be supported to provide the reliable evidence on comparative efficacy needed to enable clinicians to make informed treatment decisions. Analysis, presentation and interpretation of the results of independent studies are also likely to be more objective than those of commercial studies. The potential for bias in commercial trials has recently been highlighted by systematic reviews and journal editorsfor example "systematic bias favours products which are made by the company funding the research" and "scientific studies can be manipulated in many ways to give results favourable to companies".

There are problems with the trial reported by Brooks and Sagar, and these are common to many PD trials, which are generally of poor methodological quality. ${ }^{2}$ In a progressive condition such as PD, it is important to evaluate the long term effects of treatment, and six months follow up is inadequate. The outcome measures used should reflect the impact of treatment on the patients' own perception of their functioning and quality of life, not that of clinicians as with the Unified Parkinson's Disease Rating Scale (UPDRS). It is unclear how well the data obtained from on-off diaries correlates with global quality of life. True intention to treat (ITT) analysis was not performed, since patients who withdrew from treatment were excluded from the analysis-ITT analysis requires such patients to be followed up and included in the analysis according to the arm to which they were allocated even if they have withdrawn from allocated therapy. ${ }^{6}$ Nearly 50\% more patients $(24.1 \% v 16.5 \%)$ dropped out of the entacapone arm than from the placebo arm and, in progressive diseases such as PD, dropout bias tends to favour the active treatment. ${ }^{7}$ Thus, although COMT inhibitors are welcome additions to the treatment options in PD, large, rigorously conducted comparative trials, assessing the long term impact on patient-rated measures of overall quality of life, are still needed to define their role in routine clinical practice.

K Wheatley, N Ives, R Gray University of Birmingham Clinical Trials Unit, University of Birmingham, Birmingham, UK

C Clarke

City Hospital, Birmingham, UK

Correspondence to: Professor K Wheatley, Birmingham Clinical Trials Unit, University of Birmingham, Park Grange, 1 Somerset Road, Edgbaston, Birmingham B15 2RR, UK ; k.wheatley@bham.ac.uk

Competing interests: We are investigators in the PD MED trial and thus have a vested interest in obtaining objective evidence on the best treatment for PD. CC has received honoraria for lectures, consultancy fees, and travel expenses from the manufacturers of many of the drugs discussed.

\section{References}

1 Brooks DJ, Sagar H, the UK-Irish Entacapone Study Group. Entacapone is beneficial in both fluctuating and non-fluctuating patients with Parkinson's disease: a randomised, placebo controlled, double blind six month study. J Neurol Neurosurg Psychiatry 2003;74:1071-9.

2 Wheatley K, Stowe RL, Clarke CE, et al. Evaluating drug treatments for Parkinson's disease: how good are the trials? BMJ 2002;324:1508-11.

3 PD MED: A phase III Parkinson's disease trial. www.pdmed.bham.ac.uk (accessed 17 March 2004).

4 Lexchin J, Bero LA, Diulbegovic B, et al. Pharmaceutical industry sponsorship and research outcome and quality: systematic review. BMJ 2003;326:1 167-70

5 Smith R. Medical journals and pharmaceutical companies: uneasy bedfellows. $B M$ 2003;326:1202-5.

6 Collins R, Peto R, Gray R, et al. Large-scale randomized evidence: trials and overviews. In: Weatherall D, Ledingham JGG, Warrell DA, eds. Oxford Textbook of Medicine, Volume 1. London: Oxford University Press, 1996:21-32.

7 Gray R, Stowe RL, Hills RK, et al. Non-random drop-out bias: intention to treat or intention to cheat? [Abstract] Control Clin Trials 2001;22:38S-39S

\section{Portal-systemic shunts, manganese, and parkinsonism}

I read with interest the article by Yoshikawa and colleagues. ${ }^{1}$ The authors reported the case of a 44 year old woman with hereditary haemorrhagic telangiectasia (Rendu-OslerWeber disease) involving the liver, who had raised serum concentrations of manganese, hyperintense areas in the basal ganglia on Tl weighted magnetic resonance images, and levodopa unresponsive parkinsonism. Naturally, I agree that the parkinsonism in this case is most probably related to portalsystemic (portal-venous) shunts. There are, however, two points that deserve clarification.
First, it is not entirely clear whether their fig 2 (left panel) shows portal-systemic or arteriovenous shunts. The authors say that the figure shows a selective angiogram of the superior mesenteric artery. If that were the case, there should not be a "feeding artery" involved in the intrahepatic shunts (as they state in the legend to fig 2). Instead, the figure would show the portal vein and portalsystemic shunts (that is, portal phase of the angiogram). If, on the other hand, the catheter were in the coeliac artery (as they mention in the text), then the figure would probably correspond to the arterial phase of the angiogram and show a feeding artery (the hepatic artery) and arteriovenous (not portalsystemic) shunts. Interestingly, there is evidence to suggest that both types of shunt may be necessary for the development of neurological complications in the presence of an intact (or mostly preserved) hepatic parenchyma. ${ }^{2}$ Thus excessive quantities of potentially toxic substances (for example, ammonia, manganese) passing directly from the gut to the systemic circulation through portal-systemic shunts could be rapidly cleared by a normal liver as long as the hepatic arterial blood flow is adequate.

Second, Yoshikawa and colleagues claim that the parkinsonism of their patient was induced by manganese. While this is a reasonable working hypothesis, the authors provide no direct evidence supporting such a statement. The fact that serum manganese was raised does not necessarily imply that manganese played a key role in the pathogenesis of parkinsonism. Indeed, their patient lacked various clinical features often seen in cases of manganese induced parkinsonism ${ }^{3}$ (for example, cock walk and propensity to fall backwards).

Levodopa unresponsive parkinsonism is a well known manifestation of chronic nonWilsonian hepatocerebral degeneration. ${ }^{4}$ Although blood concentrations of ammonia were within the normal range in the case reported by Yoshikawa and colleagues, the possibility of transient abnormal increases of ammonia occurring particularly after meals was not investigated.

$R$ de la Fuente-Fernández

Division of Neurology, Hospital A Marcide, Estrada San Pedro-Catabois s/n, 15405 Ferrol, A Coruña, Spain

Correspondence to: Dr Raúl de la Fuente-Fernández, rfuente@medynet.com

\section{References}

1 Yoshikawa K, Matsumoto M, Hamanaka M, et al. A case of manganese induced parkinsonism in hereditary haemorrhagic telangiectasia. J Neurol Neurosurg Psychiatry 2003;74:1312-14.

2 Yilmaz S, Kirimlioglu V, Katz D, et al. An attempt to decrease ammonia levels after portacaval anastomosis in dogs: hepatic periarterial neurectomy. Dig Dis Sci 2002;47:1943-52.

3 Calne DB, Chu NS, Huang CC, et al. Manganism and idiopathic parkinsonism: similarities and differences. Neurology 1994;44:1583-6.

4 Adams RD, Victor M, Ropper AH. Principles of neurology, 6th ed. New York: McGraw-Hill, 1997.

\section{Authors' reply}

We are pleased to have an opportunity to comment on the important issues raised by Dr de la Fuente-Fernández regarding a case of hereditary haemorrhagic telangiectasia 
with parkinsonism. Raised serum manganese combined with the abnormal findings in cranial magnetic resonance imaging and abdominal angiography were the rationale for our conclusion that the parkinsonism in our patient was induced by manganese that had accumulated because of portal-systemic shunting.

About the angiogram: the angiogram of the superior mesenteric artery presented in our manuscript showed a dilated feeding artery, a dense mottled hepatogram, and early filling of the hepatic vein. These findings concerned the arterial phase. The intrahepatic arteriovenous shunts were definite diagnostic evidence of hereditary haemorrhagic telangiectasia but not of portal-systemic shunts. We therefore agree with Dr de la FuenteFernández that we should have presented another angiogram in the portal phase showing a hypoplastic portal vein with abnormal vessels between the mesenteric and inferior vena cava to confirm the portal-systemic shunt.

About the parkinsonism: after the failure of treatment by levodopa, we took other measures to relieve the parkinsonism; for example, we persuaded the patient to avoid manganese-rich foods such as blueberries. Fortunately, her serum manganese gradually decreased below the normal upper limit during the next six months, and her neurological symptoms became less prominent. Alleviation of parkinsonism in inverse proportion to serum manganese concentrations suggests that the parkinsonism in this case may have been caused by manganese accumulation, and that the patient was in the early stage of manganese intoxication in which neurological symptoms were incomplete and partially reversible.

About transient hyperammonaemia: we searched for cases of hyperammonaemia related parkinsonism, and finally found a case with portal-systemic encephalopathy and parkinsonism which disappeared after treatment of the portal-systemic shunting. ${ }^{1}$ The mechanism of parkinsonism in that case is certainly open to debate, as hyperammonaemia is generally thought to cause disturbance of consciousness or negative myoclonus rather than parkinsonism. We do not deny the possibility that our patient may have had a transient increase in serum ammonia, though it seems unlikely when there had never been a disturbance of consciousness.

K Yoshikawa, M Nakagawa

Department of Neurology, Research Institute for Neurological Diseases and Geriatrics, Kyoto Prefectural University of Medicine, 465 Kawaramachi-

hirokoji, Kamigyo-ku, Kyoto 602-8566, Japan

Correspondence to: Dr K Yoshikawa kyoshika@koto.kpu-m.ac.jp

\section{Reference}

1 Federico P, Zochodne DW. Reversible parkinsonism and hyperammonaemia associated with portal vein thrombosis. Acta Neurol Scand 2001;103:198-200.

\section{Intraventricular assessment of preoperative electrographic recordings}

The paper by Song et al ${ }^{1}$ describes the placement of intraventricular arrays with endoscopic assistance for preoperative electrographic recordings for epilepsy surgery. The $4.2 \mathrm{~mm}$ external diameter rigid endoscope was introduced up to the temporal ostium from where the arrays were advanced until a point of resistance was felt.

In our paper ${ }^{2}$ we reported the use of a $1.2 \mathrm{~mm}$ outer diameter semirigid endoscope to explore the contents of the ventricles prior to electrode placement, with direct visual assessment of the final electrode position, which helped us obtain appropriate preresection electrographic recordings. Perhaps it would be more convenient to use semirigid endoscopes or slim fibrescopes to fully visualise the ventricle as well as flexible arrays to avoid electrode displacement resulting in unintentional cerebral lesions.

O H Jiménez

Dept Neurosurgery, Hospital General "Dr. Miguel Silva", Secretaría de, Salud de Michoacán, Mexico

N Nagore

Dept Neurosurgery, Universidad Michoacana de San Nicolás de Hidago, Morelia, Michóacán, CP 58000,

Correspondence to: $\operatorname{Dr} O$ Jimenez, ohjv@yahoo.com.mx

\section{References}

1 Song JK, Abou-Khalil B, Konrad PE. Intraventricular monitoring for temporal lobe epilepsy: report on technique and initial results in eight patients. J Neurol Neurosurg Psychiatry 2003;74:561-5.

2 Jiménez $\mathrm{O}$, Leal R, Nagore N. Minimally invasive electrodiagnostic monitoring in epilepsy surgery. Br J Neurosurg 2002;16:498-500.

\section{Parkinsonism and persistent vegetative state after head injury}

Matsuda et al recently reported three patients with a persistent vegetative state (PVS) after severe head injury who, after recovering from prolonged disturbance of consciousness, presented parkinsonian features (mainly rigidity and hypokinesia) which improved after levodopa treatment. ${ }^{1}$ MRI studies showed lesions in the dorsolateral midbrain and cerebral peduncles suggesting axonal injury involving the dopaminergic system (substantia nigra and ventral tegmental area). Similar observations were made in a series of 125 patients with severe vegetative state following head injury (survival time $1-10$ years). Nineteen of 49 patients surviving in fully developed or mild recovery stages of PVS initially presented with severe to moderate, mainly symmetrical, parkinsonian symptoms (amimia, rigidity, hypokinesia, convergence disorders). Following levodopa treatment, 11 patients showed incomplete and four full improvement of both the PVS and parkinsonism, while four patients showed complete recovery from both syndromes. However, in 15 patients-despite good recovery from the initial PVS and other neurological symptoms (spasticity, frontal and cerebellar symptoms), and long term levodopa treatment-a progressive parkinsonian syndrome (rigidity, hypokinesia) developed; in six patients this was associated with unilateral or bilateral resting tremor. In MRI studies done in 34 patients, 32 showed unilateral or bilateral lesions in the midbrain involving both the dorsolateral tegmentum and the cerebral peduncles. ${ }^{2}$

Neuropathological studies were undertaken in 32 patients surviving without essential improvement of the PVS for at least two months after head injury. Parkinsonian syndromes were severe in seven, moderate in five, and mild in four. ${ }^{3}$ In addition to older haemorrhages or necroses in the striatum $(n=6)$, globus pallidus and thalamus $(n=8)$, all brains revealed multiple lesions in the rostral brain stem with unilateral or bilateral focal lesions in the substantia nigra, vascular lesions in the lateral and dorsolateral midbrain in seven, and symmetrical postanoxic cellular depletion and gliosis or unilateral necroses in the substantia nigra in one case each. In nine cases, there was a good correlation between the severity of clinical parkinsonian signs and the severity and extent of nigral lesions; three patients showed severe parkinsonian signs associated with only mild nigral damage, but there was severe bilateral damage to the globus pallidus in two. In four patients the expression of clinical parkinsonian signs was more severe than the anatomical lesions, in particular the damage to the substantia nigra. The distribution pattern of the brain stem lesions correlated with the sequelae of transtentorhinal shifting caused by increased intracranial pressure; direct or "primary" traumatic lesions to the oral brain stem usually cause acute death, as seen in two young men with rupture of the diencephalon and acute haemorrhage into the substantia nigra or midbrain following severe and acute fatal head injuries. However, in rare patients with long survival following head injury, symmetrical necrosis of the substantia nigra without a clinical parkinsonian syndrome has been reported. ${ }^{4}$

The clinical phenotype of post-traumatic parkinsonism often resembles that in postencephalitic parkinsonism, both showing akinesia, rigidity, hypomimia, rare tremor, and optomotor and vegetative disorders. Both the lesion pattern and the therapeutic efficacy of long term levodopa treatment suggest a dysfunction of the striato-nigral dopaminergic system which, however, may show progressive decompensation in some patients with long lasting PVS after severe head injury.

$\mathrm{K} A$ Jellinger Institute of Clinical Neurobiology, Kenyongasse 18, A-1070 Vienna, Austria

Correspondence to: Dr Kurt A Jellinger, kurt.jellinger@univie.ac.at

\section{REFERENCES}

1 Matsuda W, Matsumura A, Komatsu $Y$, et al. Awakenings from persistent vegetative state: report of three cases with parkinsonism and brain stem lesions on MRI. J Neurol Neurosurg Psychiatry 2003;74:1571-3.

2 Kothbauer P, Gerstenbrand G, Jellinger K. Concerning the question of posttraumatic parkinsonian syndromes. Meeting of the Austrian Parkinsonian Society, Vienna, 1977. RocheFortbildungs-Service, 1977:1-6.

3 Jellinger K, Seitelberger F. Protracted posttraumatic encephalopathy. Pathology, pathogenesis, and clinical implications. J Neurol Sci 1970;104:51-94.

4 Huhn B, Jakob H. Traumatic brain stem lesions with long-term survival. Contribution to the pathology of substantia nigra and the pontine syndrome. Nervenarzt 1970;41:326-34.

\section{Authors' reply}

We greatly appreciate the thoughtful comments offered by Dr Jellinger, and his interest in our report of three cases in a persistent vegetative state (PVS) after severe head 
injury, who recovered from a prolonged disturbance of consciousness after they were given levodopa. ${ }^{1}$

Jellinger et al reports that in cases of prolonged post-traumatic coma the brains showed multiple lesions of primary and secondary traumatic origin and that the highest incidence of lesions was found in the rostral brain stem. These were considered to be almost exclusively of secondary origin, resulting from cerebral and peripheral circulatory disorders, post-traumatic oedema, and increased intracranial pressure. Primary (direct) traumatic lesions to the rostral brain stem usually cause acute death. ${ }^{2}$ In contrast to this report, the brain stem injuries in our cases suggested by MRI may have been the primary traumatic lesions. All these cases showed high intensity lesions in the dorsolateral midbrain on T2 weighted MRI. ${ }^{1}$ These findings implied that the midbrain was injured by tentorial compression induced by translatory and rotatory acceleration when the cranium was struck in its sagittal axis, or by posterolateral damage. MRI findings, particularly in the acute stage, are useful for evaluating primary brain damage. ${ }^{34}$ Furthermore, another distinctive feature of our cases was that the anatomical distribution of the lesions was not multifocal but was localised in the cerebral peduncle or the dorsolateral midbrain, implying diffuse axonal injury involving the substantia nigra or the ventral tegmental area. ${ }^{1}$ The neuroradiological findings, the clinical features of extrapyramidal dysfunction, and the efficacy of levodopa treatment all strongly suggest that the dopaminergic pathways were selectively damaged and caused defects in the nigrostriatal, mesocortical, or mesolimbic system.

As Dr Jellinger indicates, progressive decompensation in levodopa treatment is a considerable problem. However, not all our patients have required permanent medication; an example is case 1 in our report, whose recovery was sustained even after the levodopa treatment was discontinued. Some patients may need levodopa only as a trigger agent at the start of treatment to interrupt the vicious cycle of exhaustion of neurotransmitter. However, discriminating which cases fall into this category is very difficult and withdrawal of medication involves ethical problems.

In recent neuropathological and neuroradiological studies on PVS after traumatic brain injury, ${ }^{4-6}$ the most common structural abnormalities were diffuse axonal injury involving the corpus callosum, the dorsolateral aspect of the rostral brain stem, ${ }^{5}$ and the thalamus. ${ }^{6}$ Although the clinical features will vary in such cases, a take-home message which we learned from our three cases is that in any group of patients with PVS after severe head injury there may be some whose dopaminergic systems may have been selectively damaged; such individuals may respond to levodopa treatment. It is necessary to accumulate a great deal more clinical experience and data to elucidate the pathogenesis and pathophysiological mechanism of posttraumatic PVS. We respect Dr Jellinger's careful observations and descriptions of his cases of prolonged post-traumatic coma, and look forward to further views from him on this topic.

W Matsuda, Y Komatsu Department of Neurosurgery, Tsukuba Medical Centre Hospital, 1-3-1 Amakubo, Tsukuba, lbaraki 3050005, Japan
A Matsumura, K Yanaka Department of Neurosurgery, Institute of Clinical Medicine, University of Tsukuba, 1-1-1 Tennodai, Tsukuba, Ibaraki 305-8575, Japan

Correspondence to: Dr Wakoto Matsuda, wako@mua.biglobe.ne.jp

\section{References}

1 Matsuda W, Matsumura A, Komatsu Y, et al. Awakenings from persistent vegetative state: report of three cases with parkinsonism and brain stem lesions on MRI. J Neurol Neurosurg Psychiatry 2003;74:1571-3.

2 Jellinger K, Seitelberger F. Protracted posttraumatic encephalopathy. Pathology, pathogenesis, and clinical implications. I Neurol Sci 1970;104:51-94.

3 Matsumura A, Mitsui I, Ayuzawa S, et al. Prediction of reversibility of the brain stem dysfunction in head injury patients. In: Nakamura N, ed. Recent advances in neurotraumatology. Tokyo: Springer-Verlag, 1993:192-5.

4 Matsumura A, Meguro K, Shibata Y, et al. Persistent vegetative state [letter]. J Neurosurg 1998:89:895-6.

5 Kampfl A, Franz G, Franz A, et al. The persistent vegetative state after closed head injury: clinical and magnetic resonance imaging findings in 42 patients. J Neurosurg 1998;88:809-16.

6 Adams JH, Graham DI, Jennett B. The neuropathology of the vegetative state after an acute brain insult. Brain 2000;123:1327-38.

\section{BOOK REVIEWS}

\section{Year book of neurology and neurosurgery 2003}

Edited by Scott R Gibbs and Ashok Verma. Published by Mosby, Philadelphia, 2003 , pp 337, £73.99 (hardback). ISBN 0-32302058-5

Every year, countless journals publish myriad neurology and neurosurgery papers. There is immense attraction in the notion of a single volume yearbook that selects and comments upon the best. So, how well does the Yearbook of neurology and neurosurgery succeed in informing about significant advances in knowledge outside my own subspecialty area for 2003? The editors draw their selection from a survey of 500 journals, with something from most of those with big impact. Thirty seven associate editors assisted by reviewing the various subspecialty areas; of these all except 11 come from North America, of whom 9 are neurosurgeons rather than neurologists, an intriguing imbalance.

Papers selected cover every conceivable subspecialty, and sometimes the inconceivable. New gene mutations abound, illuminating case histories are provided, we learn that the visual cortex is hyper-excitable in migraineurs, and about informed consent in neurosurgery, and we are treated to pictures of new cranial remodelling devices for treating craniosynostosis. To provide a critical review of such a diversity of subject matter would be an impossibility. All one can do is to congratulate the editors for highlighting a selection of topics that opens one's eyes to the dazzling diversity of our specialty. Nevertheless, you would not go to a yearbook for a comprehensive review of developments in a particular subspecialty. Therefore, this is essentially armchair reading, and none the less useful for that.
Each article is summarised in half a page or so under the headings introduction (or background), methods, results, and conclusion. This is followed by a brief editorial comment, often interesting and pithy. At least some of this signed editorial comment is derived verbatim, or with only minor paraphrasing, from editorial comment in the journal originally publishing the chosen paper. ${ }^{1}$ So whose opinion are you really reading in the yearbook?

Although interestingly informative outside one's subspecialty, one does need to ask whether the concept of a single volume yearbook isn't becoming submerged by the sheer volume of potentially eligible papers published each year. And, although this 2003 yearbook arrived on my desk in December 2003, it predominantly covers papers published in 2001, with some from early 2002, and an occasional hangover from 2000. So, it isn't that up to date. I guess libraries will buy it, partly out of habit. But for individuals, $£ 74$ is a steep price for neurological coffee table reading.

M Donaghy

\section{Reference}

1 Donaghy M. Assessing the risk of drug-induced neurological disorders: statins and neuropathy. Neurol 2002;58:1321-2.

\section{Catatonia: a clinician's guide to diagnosis and treatment}

Max Fink, Michael Alan Taylor. Cambridge: Cambridge University Press 2003, pp 210, $£ 50.00$ (hardback). ISBN 0-521-82226-2.

This nicely produced book reviews one of the historically most interesting, but clinically still very important, disorders of neuropsychiatry. Catatonia, described by Kahlbaum in the latter half of the 19th century, was hijacked by Kraepelin to be incorporated into his concept of dementia praecox, and almost disappeared from the literature in the first half of the 20th century, being finally eclipsed by the introduction of effective psychotropic drugs thereafter. But, as Fink and Taylor explore here, catatonia as a diagnosis is still a diagnostic challenge, with causes far beyond schizophrenia and a syndrome with effective treatment, notably, but not exclusively electroconvulsive therapy (ECT).

For those interested in the cerebral basis of psychiatry, a condition with the main presenting signs of mutism, immobility, negativism, posturing, stereotypy, and echophenomena cannot fail to attract attention, and the many faces of catatonia (title, chapter 3) are an olla podrida of neuropsychiatry. It is refreshing to find reference to Leonhard's work and the cycloid psychoses in a text from American authors, who are thoroughly appreciative of the European literature on their subject, and shyly critical of DSM-IV. Their overall conclusions are clear. Catatonia is a common stable syndrome, neuroleptic malignant syndrome is malignant catatonia, catatonia is not usually associated with schizophrenia, and it is a syndrome of motor dysregulation with a good prognosis-if identified and treated early. This book is a pleasure to read, but should be on the imperative reading list for all psychiatric trainees to inform them about the history of their discipline, the importance of neuropsychiatry, and how to write clearly.

M R Trimble 
New Oxford textbook of psychiatry, vols 1 and 2

M G Gelder, Jaun Lopez-lbor Jr, Nancy C Andreasen, eds. Oxford: Oxford University Press 2003, pp 2432, £125.00. ISBN 0-19852810-8

The New Oxford textbook is the latest and largest from the Oxford textbook of psychiatry's stable. The book was originally published in 2000 and has recently appeared in paperback. This is the best modern British textbook of psychiatry. It is over 2000 pages long and comes in two stout volumes. The international editorship is led by Michael Gelder, Emeritus Professor of Psychiatry at Oxford, with Spanish (Jaun Lopez-Ibor) and American (Nancy Andreasen) co-editors. The book is inevitably based on a myriad of individual contributions although the choice of contributor and standard of editing is exemplary.

The first volume covers general issues and the scientific basis of psychiatry, including a number of reviews of neurobiology. Interestingly, psychodynamic contributions have a separate section. The remainder of the first volume is taken up with coverage of the clinical syndromes of adult psychiatry, including substantial coverage of dementia.

The second volume includes review of special topics with a number of articles on aspects of the psychiatry and medical conditions. This includes a useful chapter on neurological disease by Maria Ron, and on epilepsy by Brian Toone. The remaining part of the second volume addresses the psychiatric subspecialties as well as having a substantial section on psychiatric treatments, both pharmacological and non-pharmacological.

This text is my personal first choice when I encounter a problem in the clinic that I want to look up-and I am rarely disappointed by what it says. This is a Rolls Royce of a textbook. There is a tendency to think of books as large as this one (particularly at a price of $£ 125$ even for the paperback) as suitable only for libraries. This would be a mistake. Despite its size and price this book's accessibility and comprehensiveness should make it the first choice as a postgraduate handbook, not only for psychiatrists but for neurologists and neurosurgeons too.

M Sharpe

\section{The parallel brain: the cognitive neuroscience of the corpus callosum}

Eran Zaidel, Marco lacoboni. Massachusetts: The MIT Press, 2003, pp 576, £61.95. ISBN 0262-24044-0

Roger Sperry's research on the cognitive abilities of split-brain patients following callosal section is a landmark in the study of brain-behaviour relationships. His studies firmly established the role of the corpus callosum in inter-hemispheric information transfer. What have we learned more recently about the role of the corpus callosum in cognition? In this book Eran Zaidel (originally one of Sperry's students) and neurologist Marco Iacoboni present 22 chapters based on a 1996 NATO Advanced Science Institute that attempt to answer this question. The central focus is on the classic problem of why reaction time to respond to a light flashed in either visual field differs according to whether the ipsilateral or contralateral hand is used to respond (known as the Poffenberger effect, after the psychologist who described it in 1912). This is thought to reflect callosal information transfer between the hemispheres; the book uses anatomical, physiological, and behavioural perspectives to address the question of what information is transferred and how the transfer might take place. Many chapters are accompanied by commentaries and editorial comment, giving a flavour of the debates and controversies in the field. Perhaps reflecting the long interval between the original conference and this book, more recent studies that use functional neuroimaging techniques to investigate callosal function are relatively poorly represented. However, there is still much of interest in this otherwise comprehensive volume. The chapters generally have a basic scientific focus, but chapters on multiple sclerosis, dyslexia and alexia, schizophrenia, and attention deficit hyperactivity disorder also contain much that will interest the practicing clinician.

G Rees

\section{Magnetic resonance imaging in stroke}

Stephen Davis, Marc Fisher, Steven Warach, eds. Cambridge: Cambridge University Press 2003, pp 266, £80.00. ISBN 0-521-80683-6

This book does much more than its title would suggest. Although mainly concerned with magnetic resonance imaging (MRI) in stroke, the text actually covers single photon emission computed tomography (SPECT) and positron emission tomography (PET) imaging as well and containing one of the best chapters ever written on computed tomography (CT) in stroke. The approach and content reflect the predominance of neurologists among the editors and authors, with only a few radiologists, and is really aimed at neurologists and stroke physicians.

The scene is set in the first chapter with a discussion of the limitations of clinical diagnosis of stroke and the specific role that imaging can play in diagnosing the type and cause of stroke. There is a superb chapter on CT in acute stroke, which exemplifies how the role of imaging in any diagnostic process should be evaluated. Separately, there is a chapter on CT evaluation of cerebral blood flow, a useful and practical introduction to MRI, discussion of conventional structural MR techniques such as T2, FLAIR, and gradient echo sequences, and a section on MR angiography. Much of the rest of the book (about half of it) is given over to diffusion and perfusion MRI, including its evaluation in animal models, concepts of identifying the ischaemic penumbra, evaluation of transient ischaemic attacks, selection of patients for new therapies and drug development trials, and finally a chapter on MR spectroscopy and a (very short) chapter on functional MR after stroke.

Although written by MR enthusiasts, the text is tempered with some discussion of the drawbacks of MR, such as poorer patient accessibility (compared with CT) and problems of metallic foreign bodies. It also makes the point that, despite the huge interest in MR diffusion and perfusion imaging, the precise thresholds of defining irreversibly damaged tissue and tissue at risk are yet to be determined. Some aspects of stroke MRI are not dealt with in much detail, for example classification or interpretation of white matter lesions (frequently found in stroke patients), or the identification and interpretation of microhaemorrhages on MR and how they might influence decisions regarding stroke treatment, or on using diffusion imaging to identify lesions in patients with milder strokes or at later time intervals after acute stroke (that is, not just the first few hours). There is very little on practical issues (perhaps reflecting the neurology rather than the radiology approach) such as how one assesses a stroke patient who is unable to speak prior to MR to make sure that it is safe for the patient to go into the magnet, and how one manages the patient while in the magnet with respect to factors such as oxygenation.

Some of the authors express personal views that not all readers will agree with. For example, in the chapter on assessment of a transient ischemic attack (TIA), the authors suggest that the definition of a TIA should be changed to one based on the presence or absence of certain imaging features. Although this clearly represents a personal opinion expressed by the authors, my objection to changing a classification that is so fundamental to stroke epidemiology and clinical practice is that only those with access to an MR scanner with diffusion imaging would be able to correctly diagnose a TIA using this new classification. Not only that, but the diagnosis of TIA might be dependent on the ability of the local radiologist or clinician to spot subtle features of recent ischaemia on diffusion, and on the timing of scanning after symptom onset.

I found it a little disappointing that a proportion of the perfusion images were presented in black and white when this is one technique which really requires colour display for proper interpretation and appreciation.

In summary, this is a useful textbook, particularly for neurologists or stroke physicians who need to understand more about imaging and its role in patient characterisation, decision making, and assessment of treatments in acute stroke. It's not just about MR and everybody with an interest in stroke should read the chapter on clinical efficacy of CT in acute cerebral ischaemia. At just over 250 pages it is easily digestible and yet also a useful reference. At $£ 80.00$ I think compared with other books on MR and on stroke it represents good value for money.

\section{J M Wardlaw}

\section{Cortex and mind: unifying cognition}

Joaquin M Fuster. Oxford: Oxford University Press 2003, pp 284, £47.95. ISBN 0-19514752-9

Joaquin Fuster is a distinguished American neuroscientist whose work has explored the neurophysiology of cognition, largely in animals, but with the ultimate goal of understanding how the human mind is implemented in the brain. His own research has focused particularly on the neuronal basis of working memory, revealing "memory" cells in the prefrontal cortex that help to retain the information an animal must "keep in mind" if it is to act appropriately after a delay-like the position of a covered well containing food. These prefrontal memory cells are a key component of an extensive cortical network required to maintain working memory, which also involves 
posterior brain regions closer to the sensory cortices, with a more traditional role in representing our surroundings.

Cortex and mind ranges far beyond the confines of Fuster's own experimental work. Its ambition is to describe how our key cognitive abilities-perception, memory, attention, language, and intelligence-emerge from the widely distributed cortical networks, or cognits in Fuster's terminology, which, he believes, represent the entirety of our knowledge. Fuster's interesting position is that interwoven and sometimes identical networks are involved in each of these cognitive functions, which are therefore far less well localised and less distinct than much of our contemporary quasi-phrenological thinking suggests: no cognitive function has a fully dedicated cortical area or network; conversely, a cortical network or representation is at the disposition of any and all functions.

This view has a good deal of appeal; perception is in part the reactivation of memory, attention is expressed in the changing content of perception, language and intelligence emerge from the categories that perceptual memory creates...and yet other observations, like the role of the medial temporal lobes in acquiring declarative memories, or of the fusiform gyrus in face perception or inferior parietal lobe in spatial awareness, seem to call for a more finely differentiated theory of cortical function than Fuster's general line of argument suggests.

Fuster's main thesis condemns him to repeat himself at times as he works through the roster of our cognitive functions, and he tends to a rather abstract style. But there is much fascinating information to be found here-I particularly enjoyed the closing chapters on language and intelligence-and anyone who is used to locating cortical functions on colourful scans will find cause for thought in these pages.

A Zeman

\section{The bard on the brain- understanding the mind through the art of Shakespeare and the science of brain imaging}

Paul M Matthews, Jeffrey McQuain. New York: The Dana Press 2003, pp 222, £24.50. ISBN 0-9723830-2-6

One of the great challenges of popular science writing is to convey a coherent and consistent impression of scientific ideas while avoiding confusing, specialist terminology. The most useful tools for this task are metaphor and pictures. The Dana Press, publisher for the Charles A Dana Foundation, has as its mandate "the provision of information about the personal and public benefits of brain research". With The bard on the brain, they have chosen to use the voice of William Shakespeare, the master craftsman of metaphor, to introduce the areas of human cognition that have attracted the most attention in recent functional imaging research. The logic behind this approach is that, as the authors explain, "Shakespeare's genius derives from his keen insight into the human mind" and that, in functional imaging, "brain scientists finally have the means to address questions that Shakespeare so eloquently put forward four centuries ago".

The book is a play in seven acts, each of which tackles a different field of research in cognitive neuroscience, including perception, language, the inner world of memory and emotions, and the breakdown of the mind in certain neuropsychiatric disorders. Within these acts, each scene examines a particular feature of the mind and illustrates how Shakespeare dissected and explored it in his own laboratory - the theatre. The scene opens with a quotation from a chosen play and a brief synopsis of the plot before moving on to discuss the hard neuroscience underlying this cognitive phenomenon as revealed by the latest neuroimaging techniques. For example, in discussing the role of the frontal lobes in attention shifting and the planning of behaviour, the example is chosen of Prince Hal, the wayward, youthful heir of Henry IV who purposely turns from the influence of Sir John Falstaff and his frivolous drinking companions in order to develop the resolve and strength of character which will later serve him well as King Henry V. This transformation is compared with the case of Phineas Gage, the 19th century rail worker who survived a dramatic penetrating injury to his cranium but consequently displayed a remarkable alteration in his personality. Recent computed tomography reconstructions of Gage's skull by Hannah and Antonio Damasio have clearly delineated the passage of the three foot tamping iron through the frontal cortex-the area "responsible for the functioning of what we call a moral sense".

The concept is an entertaining one and the authors have worked hard to bring it to life. The target audience presumably consists of people with no specialist knowledge of either Shakespeare or neurology and, if this is so, the reader will find plenty to hold his or her interest. The rich neuroscientific tableau ranges from Chomsky and language to the functional imaging of hallucinatory experience in schizophrenia, while the bite-sized chunks of Shakespeare successfully convey the bard's penetrating insight into the human psyche. The suggestion is that scientists, too, need to step outside the laboratory to find inspiration for their hypotheses. Lavish illustration with functional magnetic resonance imaging (fMRI), positron emission tomography, and single photon emission computerised tomography images, alongside numerous performance photos from well known theatre companies, give the book an enticing, coffee table appeal.

However, the book suffers from the contortions undergone in order to link the Shakespearian poetry to the scientific project. Take, for example, the use of Macbeth's grasping at an illusory dagger to introduce a discussion of the cerebellar control of complex motor acts, or the soliloquy from Hamlet's murderous uncle, Claudius, which begins "O, my offence is rank, it smells to heaven" as a cue to show fMRI pictures of "areas of the brain that become active with smell". In addition, the simplistic, rather than simplified, portrayal of functional imaging is coupled with brain images that are often unlabelled and poorly explained, giving the impression of a gaudy backdrop used to distract from an empty plot. The inherent danger in this approach is that, instead of facilitating public understanding of neuroscience, an aura of charmed infallibility is created. A brief mention of some of the limitations of functional imaging techniques would have helped to avoid this pitfall.

On balance, where this book succeeds, it does so due to the infectious enthusiasm of the authors. The tortuous metaphors and fancy pictures do not help much. Dialogue between science and literature has come a long way since CP Snow gave his famous Rede Lecture on the two cultures in 1950. Non-scientists are devouring popular science books-perhaps scientists need to reciprocate the attention. The Bard on the brain could certainly be instrumental in encouraging us to get to the theatre more often.

C Butler

\section{Parkinson's disease, diagnosis \& clinical management}

Stewart A Factor, William J Weiner. New York: Demos Medical Publishers 2002, pp 716, \$175.00. ISBN 1-888-799-50-1.

This multi-authored tome on Parkinson's disease (PD) admirably captures the complexity and diversity of the many clinical challenges and scientific problems that surround this common neurodegenerative disorder. Contributions over 58 chapters embrace an international body of expertise, with a pronounced north American emphasis, and range from discussing the early history of the condition to a welcome section on social issues, with in depth attention paid to the clinical presentation, including psychological features, structural and chemical pathology, theories of aetiopathogenesis, drug, surgical, and other treatments, and atypical and familial forms of parkinsonism. The text is generously referenced and well-illustrated with black and white figures. There are impressive chapters on the contribution of MPTP to our understanding of PD, genetic and environmental factors, and the drug classes employed in treatment as well as the complications of treatment, including dyskinesia and motor fluctuations. Proper attention is given to the management of psychosis and cognitive decline, with discussion of the relationship of these features in PD to dementia with Lewy bodies and Alzheimer type pathology. Future avenues of treatment, including neuroprotection and gene therapy, are also covered in this near encyclopaedic compendium, which is highly recommended for all those who treat patients with PD in neurology, geriatrics, and old age psychiatry departments, as well as research scientists in the field, and it should be required reading for all neurological trainees.

R Pearce

\section{Principles and practices of emergency neurology-handbook for emergency physicians}

S M Shah, K M Kelly. Oxford: Oxford University Press, 2003, pp 454, £40.00, (paperback). ISBN 0521009804

This is a handbook based on an earlier larger book, Emergency neurology: principles and practice, in response to enquiries from emergency medicine residents about whether a handbook, based on this main text, would be available. This is the result. Whether it is justified in calling itself a handbook is hard to say. The area covers three of my hands (small!). It runs to over 400 pages with approximately 50 authors. It covers neurological examination and neurodiagnostic 
testing, common neurological presentations, for example headache and weakness, specific neurological conditions, for example multiple sclerosis and cerebrovascular disease, neurological trauma, paediatric neurological emergencies, pregnancy related neurological emergencies, neurotoxicology, and brain death. So, it attempts a comprehensive coverage.

The editors consider it to be symptom based, although this is not always achieved. It has many tables, good illustrations, and management of algorithms with "pearls and pit falls" at the end of every chapter.

The neurological examination is done poorly, particularly the cranial nerves. This needs to be done with pictures of the lesions, their causes, and the anatomy, based around the common emergency presentations in A\&E. Although British neurologists would disagree with some of the advice given, most of the text is reliable and clear. (For instance, in the chapter on myasthenia gravis, it states "useful gauges include pulse oximetry, peak expiratory flow and PCO2 measurement", which are all poor gauges of impending ventilatory failure and vital capacity is the most important measurement in this respect.)

The most disappointing feature is that the chapters are not adequately focused on emergency conditions. The chapter on movement disorders covers virtually the whole spectrum of chronic movement disorders without specifically concentrating on the common acute presentations, such as drug induced dystonia with oculogyric crisis and hemiballismus, which are likely to come to A\&E. Unfortunately the editors and authors have failed to produce a sufficiently concise account of emergency conditions to make this book really useful. It needs to be much briefer and appropriately focused to achieve its aim and it would be better as a pocket book, similar to the edition of the Oxford text of medicine, which seems to occupy the pockets of most medical students! If only we could achieve the same for the pockets of medical SHOs in emergency neurology, things might improve!

D E Bateman

\section{Duchenne muscular dystrophy, 3rd edn}

Alan E H Emery, Francesco Muntoni. Oxford: Oxford University Press, 2003, pp 280, £79.50 (hardback). ISBN 0-19-851531-6

Quite simply, this monograph is essential reading for anybody involved with this devastating condition, and indeed for those involved with any form of muscular dystrophy, whether in the clinic or in the laboratory. Duchenne muscular dystrophy (DMD) is the archetypal dystrophy. It is because the clinical course is so stereotyped that it was the first of the dystrophies to be defined clearly, over a century ago. The historical journey from the first clinical descriptions to our present state of knowledge forms the core of this book, with side branches relevant to the identification of other specific forms of dystrophy, particularly the limb girdle dystrophies. The nihilist may suggest that all of this knowledge has as yet failed to find a cure, but for the clinicians intimately involved with these patients we can now do more than ever to provide an improved quality of life. There is of course great hope that "genetic engineering" will lead to a cure, but patients and their families cannot live on hope alone and Professors Emery and Muntoni have elegantly summarised present management options.

The second edition was published in 1986, a matter of months before the identification of the gene involved in the disease process and its protein product dystrophin. Within a few years it became apparent that dystrophin and dystrophin associated proteins have a fundamental role in various forms of muscular dystrophy, and for a while it looked as if there might be a common mechanism of membrane fragility due to dysfunction of these membrane associated proteins. Then abnormal cytosolic proteins were found in some forms of limb girdle dystrophy and it became clear that there was no simple single disease mechanism. Despite that, altered function of membrane proteins is clearly of fundamental importance in many dystrophies and Muntoni has been at the forefront of recent discoveries relating to altered glycosylation of the membrane protein $\alpha$-dystroglycan in various forms of congenital and adult onset limb girdle dystrophies.

There is no need to describe the individual chapters in detail. In brief, the monograph covers the history of the disease (Emery being a noted medical historian), clinical features, differential diagnosis, molecular pathology, pathogenesis, genetic counselling, and management. Emery is retired from clinical practice but the clinical setting is kept up to date by his being joined by Muntoni for this timely third edition.

All those involved in the management of DMD will find something of value in this book. Some patients and families may also want to dip into it. Those interested in the history of medicine, and the evolution of modern genetic and molecular techniques, will find it a fascinating story.

Let us hope that a fourth edition, detailing the successes of genetic engineering, will not be too far off, but in the meantime there is much that can be done to alleviate the consequences of this truly awful condition.

D Hilton-Jones

\section{Mental and behavioral dysfunction in movement disorders}

Marc-Andre Bedard, Yves Agid, Sylvain Chouinard, Stanley Fahn, Amos D Korczyn, Paul Lesperance. New Jersey: Humana Press 2003 , pp 543, \$185.00 (hardback). ISBN 158829-119-7

It was not long ago that the basal ganglia were confidently asserted to have no influence on cognition, and to have only motor functions. This was the province of neurology, and the concept that they might be involved in disordered behaviour other than that referred to as movement disorders was an anathema to generations of neurologists.

As Goetz notes, in the introduction to this nicely produced book, this view ignored over a 100 years' of clinical observation, and much subsequent work, theoretical, clinical, neurochemical, and neuroanatomical, all of which underline the central role of the basal ganglia structures in regulating behaviour, in its widest sense, and hence the association between movement disorders and cognitive and behavioural dysfunction.

The openers in this text are with neuroanatomy and neurochemistry, rightly so since the impact of the discovery of dopamine and the unveiling of the new neuroanatomy of the limbic forebrain, have fundamentally altered the way we think about the brain and its functions, and should profoundly influenced clinical thinking. A chapter on the cerebellum is also included in the opening section.

The book then contains chapters on two main themes, cognition in movement disorders, including the long controversial area of links with dementia, and the neuropsychiatry of movement disorders. The main diseases discussed are the obvious eponymous ones of Parkinson's, Huntington's, and Gilles de la Tourette, as well as corticobasal degeneration. There are some curious omissions, Wilson's disease, Sydenham's chorea, and supranuclear palsy, among others. The cognitive problems embrace such topics as speech disorders and apraxias, and include chapters on animal models as well as clinical research.

The section on neuropsychiatric aspects is laid out rather differently and less systematically. A chapter on mood disorders and the pallidum, another on depression and the basal ganglia, another on psychosis and mood disorders in Huntington's disease, some disease orientated, others anatomically based. Nevertheless, the individual chapters are, for the most part, well written, and included are contributions on REM sleep behaviour disorder, psychogenic movement disorders, and obsessive compulsive disorder. A separate section is devoted to quality of life studies.

The book is a timely reminder of the growth of interest in and the clinical importance of neuropsychiatry, and quite some space in the text is given to treatment and management issues. No longer can the basal ganglia simply be viewed as structures subserving motor function, they represent drives and affects which are re-represented cortically and which propel our very being.

M Trimble

\section{CORRECTIONS}

doi: 10.1136/jnnp.2003.029074corr 1

In the review by Rockwood in the May issue of JNNP (K Rockwood. Size of the treatment effect on cognition of cholinesterase inhibition in Alzheimer's disease. $J$ Neurol Neurosurg Psychiatry 2004;75:677-85) there is an incorrect entry on the $\mathrm{x}$ axis each of the tables in figure 1 . The sixth entry should read 0.25 , instead of 0.5 . The corrected table can be viewed at http://www.jnnp.bmjjournals.com/ cgi/content/full/75/5/677/DCl

\section{doi: 10.1136/jnnp.2003.034876corr 1}

The authorship list of the letter entitled emotion process in the minimally conscious state, by Bekinsctein et al (JNNP May 2004;75:788), was incorrectly printed as T Bekinschtein, J Niklison, L Sigman, F Manes, $\mathrm{R}$ Leiguarda, J Armony, A Owen, S Carpintiero, and L Olmos. However, the correct order is as follows: $\mathrm{T}$ Bekinschtein, $\mathrm{R}$ Leiguarda, J Armony, A Owen, S Carpintiero, J Niklison, L Olmos, L Sigman, F Manes. 